\title{
Epithelial-stromal interactions in the mouse and human mammary gland in vivo
}

\author{
Hema Parmar and Gerald R Cunha
}

University of California, 3rd and Parnassus, Department of Anatomy, HSW 1323, San Francisco, CA 94143, USA

(Requests for offprints should be addressed to G R Cunha; Email: grcunha@itsa.ucsf.edu)

\begin{abstract}
This review deals with the development and hormonal responses of mouse and human mammary glands. A major focus of the review is the role of mesenchymal-epithelial interactions in embryonic mammary development and the role of stromal-epithelial interactions in mammary gland biology. Finally, we present a new model for studying growth, differentiation and hormonal response in human breast epithelium grown in vivo in nude mouse hosts. This new model involves the construction of tissue recombinants composed of human or mouse mammary fibroblasts plus human breast epithelium in polymerized collagen gels. In the model, mouse mammary fibroblasts and human breast fibroblasts appear to support the normal differentiation and growth of human breast epithelium equally. This observation raises the possibility of using mouse mammary fibroblasts from various mutant mice to assess the role of specific paracrine-acting gene products in human mammary gland biology and carcinogenesis.
\end{abstract}

Endocrine-Related Cancer (2004) $11437-458$

\section{Introduction}

The mammary gland is a useful model in which to study epithelial-stromal interactions, as these interactions are important in embryonic development, postnatal ductal growth, ductal branching morphogenesis and carcinogenesis. The mammary gland is a dynamic organ the structure of which changes throughout the female reproductive cycle. Development of the gland occurs in defined stages that are connected to sexual development and reproduction, namely embryonic, prepubertal and pubertal stages, pregnancy, lactation and involution. Two cellular compartments constitute the gland: the epithelium and the surrounding stroma, which are derived embryologically from ectoderm and mesoderm respectively. In all mammals, the mammary glands arise from localized thickenings of ventral ectoderm or epidermis. Mammary buds form by elevation of an epidermal 'mammary crest' that forms a milk line in some species. The milk line is a linear thickening of epidermis on both sides of the midventral aspect of the embryo. In the mouse at embryonic day (E)16, cell proliferation at the tip of the mammary bud elicits elongation of the primary duct, which grows toward the mammary fat pad precursor. The primary mammary duct invades the mammary fat pad at E17 and subsequently forms a small branched ductal tree. At the time of birth, 15-20 branching ducts are present within the developing murine fat pad. Stromal-epithelial interactions are responsible for rapid epithelial growth and the distinctive pattern of ductal branching morphogenesis characteristic of the mammary gland (Daniel \& Silberstein 1987).

Human and mouse mammary glands have many differences and thus will be discussed individually. The functional portion of the human mammary gland is called the terminal ductal lobular unit (Fig. 1A), whereas the major functional units of the mouse mammary glands are termed the lobuloalveolar units (Fig. 1B). The human terminal ductal lobular unit is comprised of a small group of lobules emerging from a terminal duct, and thus resembles a cluster of grapes at the end of a stem (Fig. 1A). It is organized within loose intralobular connective tissue, which in turn is surrounded by more dense interlobular connective tissue (Russo et al. 1990) (Fig. 2A, B). The mouse mammary gland, at birth, consists of the main duct with modest arborization within the stroma of the mammary fat pad; in the pubertal mouse, however, individual mammary ducts terminate in a single bulbous 

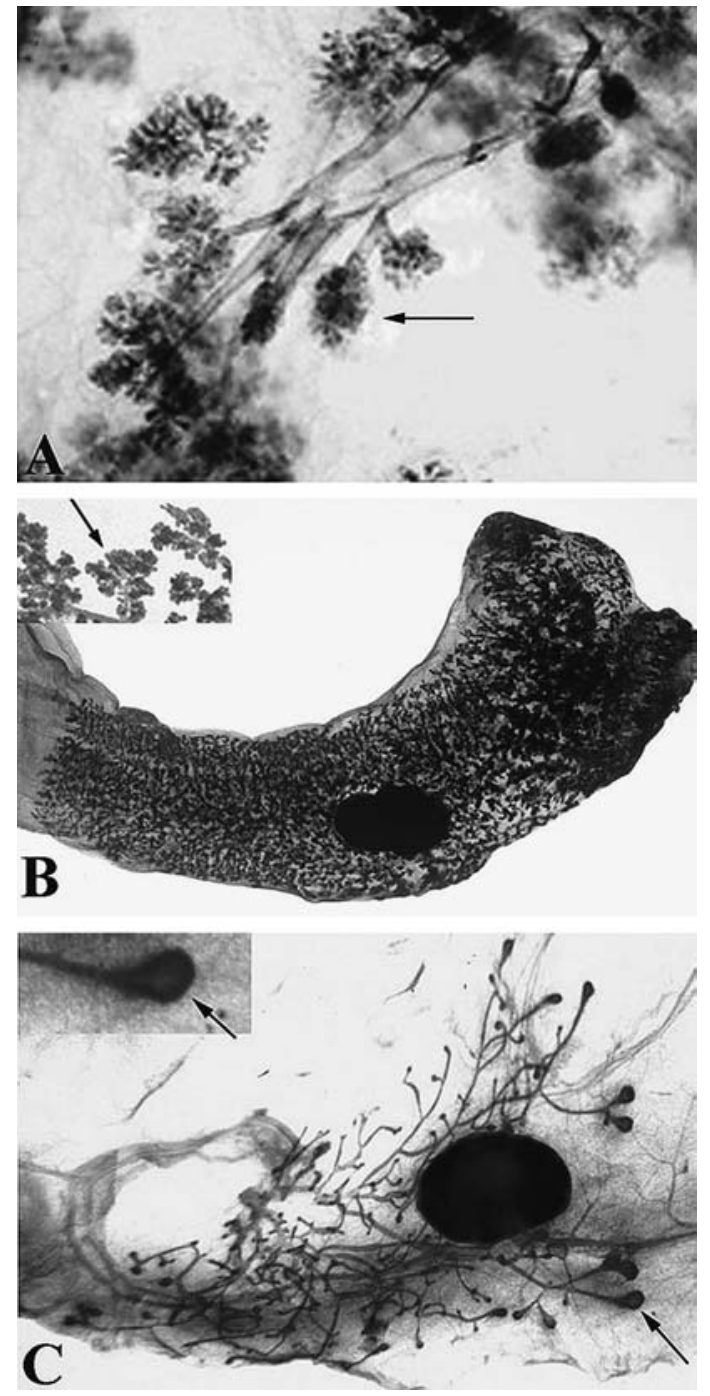

Figure 1 Whole mounts of $(A)$ mature nulliparous human breast and $(B)$ pregnant and $(C)$ pubertal mouse mammary glands. (A) The human mammary gland is composed of terminal ducts from which lobular units emerge known collectively as terminal ductal lobular units (arrowed). (From UC Davis website on Comparative pathology of mouse and human mammary gland (http://tgmouse.compmed.ucdavis.edu/srwtxt/ index.htm) by Sefton R Wellings and Robert D Cardiff with permission). (B) The pregnant mouse mammary gland, showing the major functional units termed the lobuloalveolar units (arrowed at higher magnification in insert). (C) Pubertal mouse mammary gland, showing individual mammary ducts which terminate in single terminal end buds (arrowed at high power in the insert).

terminal end bud (Fig. 1C). In the adult virgin mouse the ducts have grown to 'fill' the fat pad fully, and the end buds are no longer present; nevertheless, there is considerable space between the minimally branched ducts (Fig. 2C, D).
Histologically, the mouse mammary stroma is dramatically different from the human stroma (Haagensen 1971, Topper \& Freeman 1980). The mouse mammary gland contains a large amount of fat with small amounts of interspersed fibrous connective tissue (Fig. 2C, D). Although the human breast also contains large areas of adipose tissue, the epithelium is generally not closely associated with adipose tissue; rather, it is associated with fibrous connective tissue (Fig. 2A, B).

Both human and mouse mammary ducts contain similar epithelial cells. Each duct is composed of epithelial cells surrounding a central lumen; the cells bordering the lumen are referred to as luminal epithelial cells (Richert et al. 2000). Human and mouse luminal mammary epithelial cells express all or a subset of the following cytokeratins, which can be detected immunohistochemically: 7, 8, 11, 15, 17, 18, 19, 20 and 22 (Moll et al. 1982, Asch \& Asch 1985). Underlying the luminal epithelial cells are the myoepithelial cells (Richert et al. 2000) forming a basal layer that rests on a laminin-containing basement membrane separating the parenchymal and stromal compartments. Mouse and human myoepithelial cells express cytokeratins 5 and 14, p63 and smooth muscle $\alpha$ actin (Radice et al. 1997).

Interactions between mammary gland epithelium and the surrounding mesenchyme/stroma have been studied using tissue recombination techniques. Initial pioneering work by Klaus Kratochwil, Teruyo Sakakura and Ken De Ome established the importance of mesenchymal-epithelial and stromal-epithelial interactions in the mammary gland, from the embryo through to the adult (De Ome et al. 1959, Kratochwil 1969, 1987, Sakakura 1987).

In vitro and in vivo models have been used to investigate the role of tissue interactions in both the mouse and human mammary glands. In this review, the development of the glands of both species will be discussed, as will methods for studying their in vivo development, with an emphasis on epithelial-stromal interactions.

\section{Epithelial-mesenchymal interactions in the embryonic mouse mammary gland}

Mouse mammary epithelial buds emerge from the embryonic epidermis as a result of mesenchymal induction. This initial stage of mammary gland development is independent of systemic cues and instead depends on reciprocal signaling between epithelium and the mesenchyme. In the mouse embryo, five pairs of ectodermal placodes appear between E10 and E11. They form as distinct spots in two lines running ventrally just inside the limbs from the neck to the inguinal area. Patterns of gene expression have been established in the embryonic mouse 


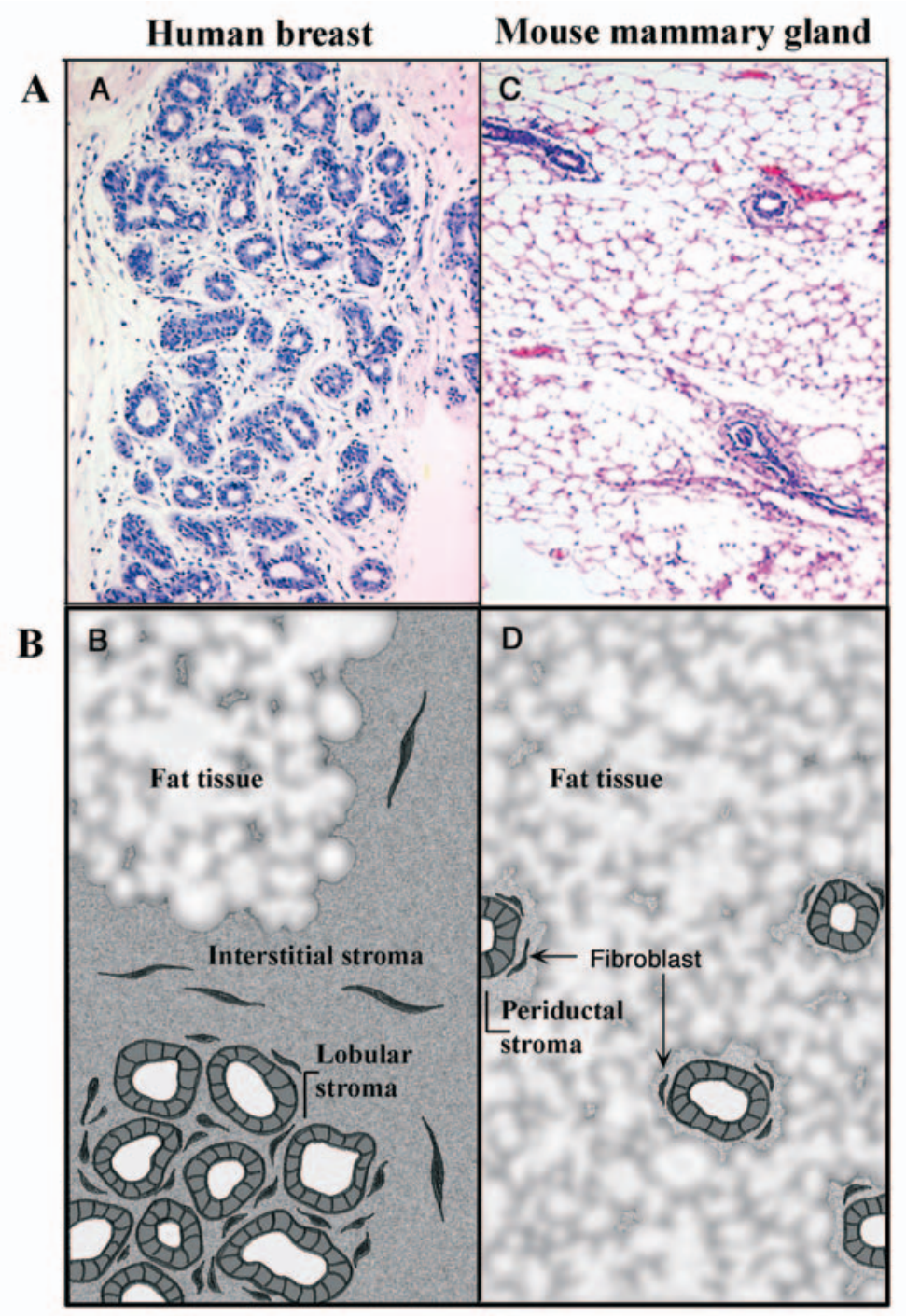

Figure 2 Comparison of human and mouse mammary glands. (A) Hematoxylin \& eosin (H\&E) stained section of human breast tissue showing a terminal ductal lobular unit comprised of ducts and acini embedded in a fibrous connective tissue stroma. (B) Schematic representation of a human terminal ductal lobular unit, emphasizing the intimate association of epithelial structures with interstitial fibrous connective tissue stroma and the more distant adipose tissue. (C) H\&E stained section of the mouse mammary gland, showing ducts imbedded in a stroma composed of adipose tissue. (D) Schematic representation of the mouse mammary gland, displaying ducts in intimate contact with fibroblasts and adipocytes. (Adapted from Ronnov-Jessen et al. 1996, with permission.)

mammary rudiment and demonstrate epithelial and mesenchymal specificity (Fig. 3).

\section{Placode formation: migration versus proliferation}

Two mechanisms of mammary placode formation have been considered. One possibility is a local increase in cell proliferation. However, careful investigation of this possibility did not reveal a high mitotic index in or around the emerging buds in comparison with the adjacent ectoderm (Balinsky 1949). Accordingly, a possible role of cell proliferation in the formation of mammary placodes has been rejected in favor of an alternative theory. Propper (1978) observed flat amoeboid cells on top of the cuboidal epithelial cells of the mammary ridge in the rabbit embryo, suggesting that cell motility (namely ectodermal cell migration) was playing a part in mammary placode formation. This idea was further supported by his observation of the 

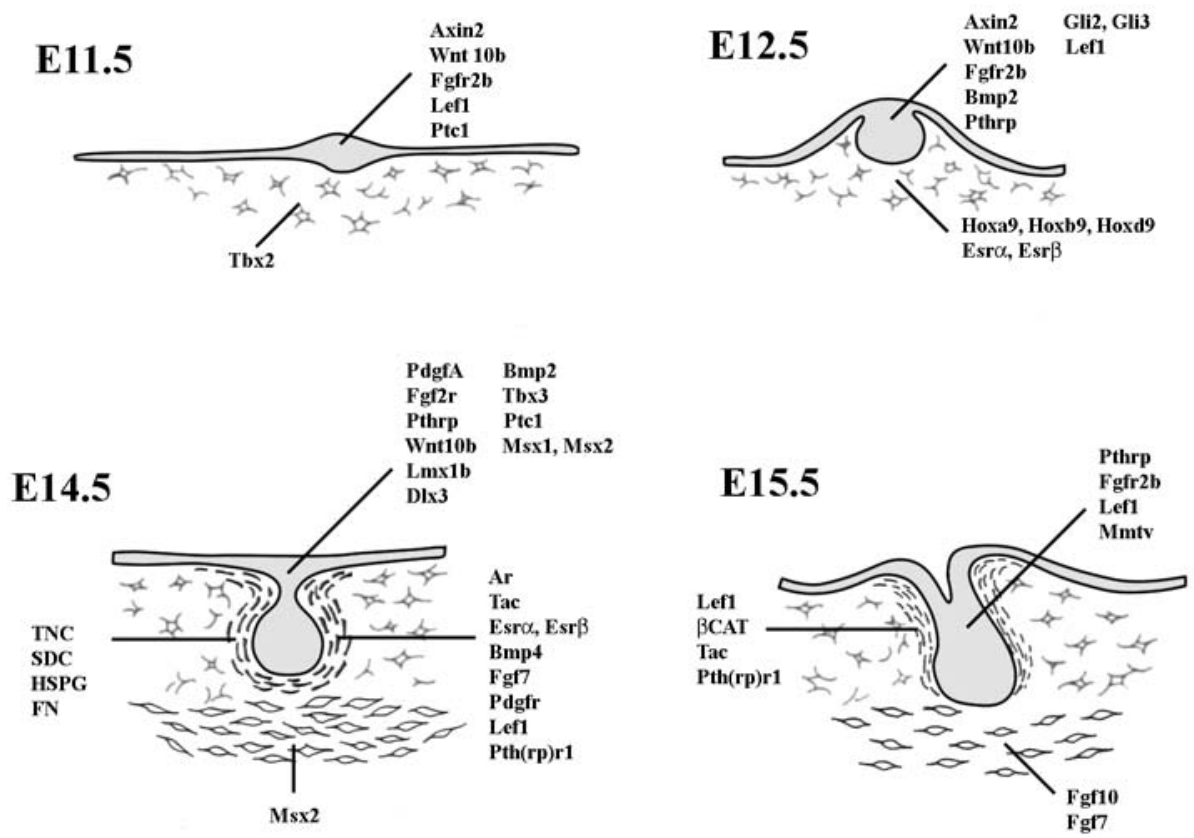

Figure 3 Genes expressed during development of the embryonic mouse mammary gland. Note that genes are expressed in a tissue-specific pattern, with many genes expressed exclusively in epithelium or mesenchyme. E11.5 to E15.5, embryonic days 11.5 to 15.5. (Adapted from Veltmaat et al. 2003, with permission.)

accumulation of charcoal particles in the forming buds within $48 \mathrm{~h}$ after their deposition on flanks of E13 rabbit embryos in culture (Propper 1978). Recent work has also shown that, in E11.5 mouse embryos, expression of the Lef1 transcription factor first appears as a short faint line at the position of each mammary rudiment (van Genderen et al. 1994). Over the following $6 \mathrm{~h}$, this area of expression changes from comet-shaped to dot-shaped (Mailleux et al. 2002). The initial expression profile and its rapid change in shape strongly suggest that ectodermal cells migrate along the presumptive mammary line to distinct places where they form the mammary placodes.

\section{Mammary placode formation: role of mesenchymal induction}

Propper and colleagues were the first to suggest that mammary mesenchyme induces the overlying ectoderm to form epithelial buds (Propper \& Gomot 1967, 1973, Propper 1968). Using morphological criteria, they showed that epithelial buds formed when non-mammary ectoderm was cultured in vitro in association with embryonic mammary mesenchyme (Fig. 4b). However, he was unable to examine the induced epithelial buds for expression of mammary-specific markers. This work was repeated years later by Cunha et al. (1995), who grew embryonic epidermis from midventral or dorsal sites of 13-day rat embryos in association with 13-day embryonic mouse mammary mesenchyme. The resultant tissue recombinants were grafted into virgin and lactating female athymic mouse hosts. In both types of host, these tissue recombinants formed keratinized skin with hair follicles and sebaceous glands. Associated with these epidermal structures were mammary ducts lined by columnar secretory epithelial cells underlain by myoepithelial cells expressing smooth muscle $\alpha$-actin (Cunha et al. 1995). When grown in lactating female hosts, the induced mammary epithelial cells formed lobuloalveolar structures and expressed casein and $\alpha$-lactalbumin. These data confirmed Propper's initial findings and demonstrated that embryonic mammary mesenchyme induces and specifies mammary epithelial differentiation from epidermis, both morphologically and functionally.

Mammary gland identity is determined in the mammary bud as early at E12, as shown by tissue recombination studies in which salivary gland mesenchyme (SGM) was combined with mammary gland epithelium (MGE) (Fig. 4c). The resulting SGM + MGE grafts developed a ductal branching pattern resembling the salivary gland. However, functional cytodifferentiation of the epithelium was indicative of mammary gland. In lactating hosts, the SGM + MGE recombinations responded to endogenous hormonal stimulation and synthesized the milk protein, $\alpha$-lactalbumin (Sakakura et al. 1976). 


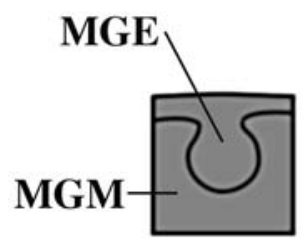

a.
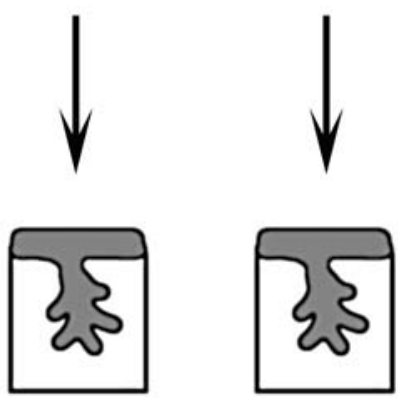

Mammary Gland Differentiation

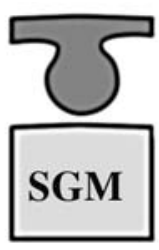

c.

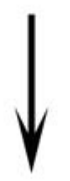

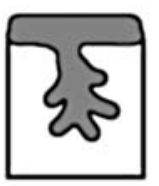

Figure 4 Summary of mammary tissue recombinant experiments. (a) Control homotypic tissue recombinants composed of embryonic mammary mesenchyme (MGM) plus mammary epithelium (MGE) continue development both in vitro and in vivo and give rise to recognizable mammary tissue, which, under in vivo lactogenic conditions, will produce milk proteins. (b) Mammary mesenchyme can induce non-mammary epidermis to form mammary buds (Propper \& Gomot 1967, 1973, Propper 1968) that will undergo functional mammary differentiation in vivo (Cunha et al. 1995). (c) Thirteen-day embryonic mammary epithelium, when combined with salivary gland mesenchyme (SGM), forms ductal structures with branching patterns that resemble salivary gland, but which, in pregnant host, produce milk proteins (Sakakura et al. 1976). Thus mammary epithelial identity appears to be stable by 13 days of gestation. (d) Control homotypic tissue recombinants composed of embryonic epidermis plus dermis differentiate into skin.

\section{Male versus female differences in mammary gland development}

Once formed, embryonic murine mammary buds either survive and form mammary tissue in females or regress in males. In most mouse strains, androgens elicit condensation of the mesenchyme around male mammary buds and trigger destruction of the epithelial rudiment by day 16 (Fig. 5). This complex process, described by Kratochwil (1987), involves a series of reciprocal interactions between epithelium and mesenchyme.

Organ culture studies demonstrated that testosterone (and other androgens) elicit destruction of the mammary gland bud by direct action not requiring systemic factors (Kratochwil 1971). Embryonic mammary gland explants were exposed to testosterone for different periods, and the acquisition and subsequent loss of sensitivity to androgens were thereby defined. Using such methods, Kratochwil (1977) demonstrated that the embryonic mouse mammary gland is initially unresponsive to testosterone at E11 and E12, but becomes responsive to the hormone at E13. Regression is normally complete by E16. Embryonic female mammary glands that normally are not exposed to testosterone were found to regress provided testosterone was added to the medium during a time frame equivalent to days E13 to E16. Testosterone given after E16 did not trigger regression of female mammary buds. Thus the window of androgen sensitivity is restricted to E13 to E16. Acquisition of sensitivity to testosterone correlates temporally with the expression of androgen receptors (AR) in mammary mesenchyme but not in the epithelium (Kratochwil \& Schwartz 1976). Autoradiographic studies showed that the mammary epithelial bud is surrounded by a distinct population of mesenchymal cells, exhibiting nuclear concentration of $\left[{ }^{3} \mathrm{H}\right] 5 \alpha$-dihydrotestosterone (DHT). Such nuclear hormone binding was strictly confined to the mesenchymal cells (Heuberger et al. 1982). These DHT-binding cells were already detectable in the mesenchyme of 12.5-day glands and persisted thereafter (at least into the neonatal period). These data suggested that the mammary gland bud was destroyed by testosterone-activated mesenchymal cells rather than by direct hormone action.

The apposition of AR-positive mesenchymal cells to the mammary epithelial bud suggested either that the mammary epithelium attracts pre-existing AR-positive mesenchymal cells or that the epithelium induces the expression of AR in the surrounding mesenchyme. These possibilities were tested in tissue recombination studies in which AR-negative inter-bud (dermal) mesenchyme of the mammary region (not previously in contact with a mammary bud) was associated with embryonic 
In vivo development of mammary rudiments

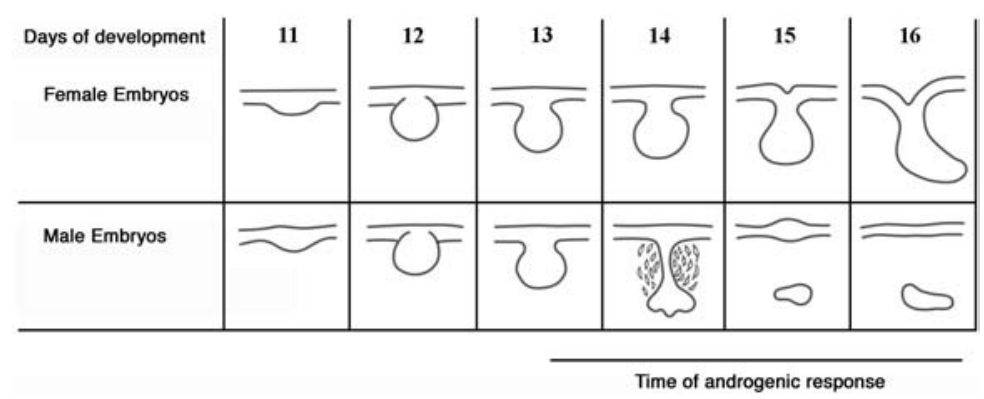

Figure 5 Sexually dimorphic development of female and male mouse mammary glands. The appearance of the mammary placodes and the formation of the buds is identical in males and females. Because of androgens produced by the fetal testes, beginning on embryonic day $(E) 13$, the male mammary gland regresses and is mostly eliminated by $E 16$. The window of sensitivity to androgens is the period E13 to E16, after which androgens cannot elicit mammary gland destruction in female mice. (Adapted from Kratochwil 1977, with permission.)

mammary, lung or salivary gland epithelium. The resulting tissue recombinations were grown for 3 days in vitro, then exposed to testosterone and processed for autoradiography. Mammary bud epithelium consistently induced AR in inter-bud mesenchyme (which is normally AR-negative) and all mammary gland epithelia became surrounded by AR-positive mesenchyme; however, when epithelia of the salivary gland or lung were combined with mammary mesenchyme, AR was not detected in the mesenchyme (Dürnberger \& Kratochwil 1980). Thus mammary epithelium specifically induces expression of AR in adjacent mesenchymal cells.

The question of whether testosterone elicits regression of mammary gland epithelium by direct action on the epithelium or by paracrine interaction mediated by mesenchymal AR was answered definitively by tissue recombination studies between mammary gland epithelium and mesenchyme of wild-type and androgeninsensitive Tfm (testicular feminization) mice. Tfm mice have a mutation in the gene encoding the AR (He et al. 1991), fail to express functional AR, and consequently are insensitive to androgens. Accordingly, the mammary glands of embryonic male Tfm mice do not undergo regression in response to endogenous or exogenous androgens. Dürnberger \& Kratochwil (1980) analyzed the four possible mammary gland tissue recombinations composed of wt and Tfm epithelium (E) and mesenchyme (M). In vitro treatment of the tissue recombinations with testosterone elicited destruction of the mammary gland epithelium only in tissue recombinations prepared with wild-type (wt) $(\mathrm{AR}+)$ mesenchyme (wt-M + wt-E and wt-M + Tfm-E), and not when AR-negative Tfm mesenchyme was used (Tfm-M + Tfm-E and Tfm$\mathrm{M}+\mathrm{wt}-\mathrm{E})$. These data demonstrated conclusively that androgens elicit mammary epithelial regression via the AR-positive mesenchyme, which in response to androgens is induced to condense around the epithelium, thus triggering epithelial regression (Dürnberger \& Kratochwil 1980).

\section{Mammary mesenchyme versus mammary fat pad}

Sakakura et al. (1982) demonstrated that two different mesenchymal tissues are involved in mammary gland development: fibroblastic cells immediately surrounding the epithelial rudiment (called mammary mesenchyme) and the fat pad precursor. The fat pad differentiates independently of mammary mesenchyme, from more deeply placed subcutaneous mesenchymal cells. The earliest appearance of the fat pad precursor tissue in mice may be traced back to E14. At this stage, a more condensed tissue lies below the mammary rudiment and, if transplanted under the kidney capsule, differentiates into fatty tissue. Mesenchyme from the prospective mammary region is able to induce mammary epithelial differentiation when combined with dorsal epidermis (Cunha et al. 1995), demonstrating that a mesenchymal signal first determines mammary epithelial identity. In addition, the mammary epithelium induces AR in the mammary mesenchyme and thereby controls the development of androgen responsiveness of the gland (Dürnberger \& Kratochwil 1980). The mammary mesenchyme and the fat pad have extremely different developmental properties. The mammary mesenchyme induces embryonic or adult mammary gland epithelium to undergo an atypical compact ductal branching, giving rise to a ductal pattern similar to that of the salivary gland (Sakakura 1987). In contrast, the mammary fat pad elicits a diffuse pattern of ductal branching morphogenesis characteristic of the adult mammary gland (Daniel \& Silberstein 1987). The mammary gland mesenchyme (MGM) has the ability to 
induce embryonic epidermis to undergo mammary morphogenesis and functional differentiation as described above (Cunha et al. 1995). The mammary fat pad has not yet been tested for its instructive ability to induce mammary gland development from embryonic or adult epithelia such as epidermis. Both mammary mesenchyme and the fat pad precursor are derived from subcutaneous mesenchymal cells that contribute to the stroma of the mammary gland. Cells of the mammary fat pad are predominantly adipocytes with a few interspersed fibroblasts. Fibroblasts are primarily found in close association with ductal basement membranes (Fig. 2D) (Cunha \& Hom 1996). Adipocytes clearly develop from the fat pad precursor, but the origin of mammary fibroblasts is unknown; they could arise from the fat pad precursor itself, mammary mesenchyme, or both. The interaction of mammary gland epithelium with adipose tissue to induce ductal growth and branching has been shown to be nonspecific, as adipose tissues from various non-mammary sites are capable of supporting mammary epithelial growth and ductal branching morphogenesis (Hoshino 1978).

\section{Epithelial-stromal interactions in the postnatal mouse mammary gland: hormonally mediated growth and development}

Mouse mammary gland development mostly occurs postnatally. Initially, the ductal system begins to develop from the nipple at the embryonic stage. At puberty, specialized structures termed the terminal end buds develop on the end of the ducts (Fig. 1C). These terminal end buds are the site of intense DNA synthesis that elicits ductal elongation (Bresciani 1968). In addition to the terminal end buds, responsible for ductal elongation, there are two other types of buds. Lateral buds develop along mature ducts, grow a short distance, and then stop because of the presence of other competing ductal elements. Alveolar buds develop in most mouse strains only in response to the hormones of pregnancy. Postnatal mammary gland development and function are highly dependent upon the actions of pituitary, adrenal and ovarian hormones (estrogen, progesterone, prolactin and corticosteroids) (Fendrick et al. 1998, Binart et al. 2000, Neville et al. 2002).

Around the time of the release of ovarian hormones at puberty (beginning at about 4 weeks of age), the terminal end buds grow into the fat pad, undergo branching morphogenesis and lay down a minimally branched mammary ductal 'tree' characteristic of the virgin state. Throughout the estrus cycle there is modest development of the ductal system. During pregnancy, dramatic out- growth of lateral and alveolar buds occurs, which culminates in development of the lobuloalveolar structures that produce milk. This rapid epithelial growth is caused by the increase in ovarian hormones (estrogen plus progesterone) and prolactin. Once weaning has occurred, the fully developed mammary gland regresses to a virginlike state. Interactions between the epithelium and stroma have important roles in mammary gland development and branching morphogenesis. These have been elucidated in part in transgenic mouse models and by the use of tissue recombination studies. Although it is the epithelial component of the mammary gland that proliferates and undergoes ductal branching morphogenesis, the mammary stroma contributes both instructive and permissive signals. This stroma consists of many cell types, which include fibroblasts, adipocytes, endothelial cells, extracellular matrix and inflammatory cells, each subject to regulation throughout the developmental cycle. The ductal growth and branching observed during puberty are elicited by estrogen produced by the ovaries. Estrogen triggers the development of end buds and stimulates epithelial DNA synthesis (Daniel \& Silberstein 1987, Silberstein et al. 1994). Complete development of the mammary gland takes place after puberty, depends on the estrogen receptor $\alpha(E R \alpha)$ and the progesterone receptor (PR), and is closely regulated by the interaction of the mammary epithelium with its stroma.

\section{Estrogen}

It has been well established that almost all aspects of mammary biology are under hormonal regulation. Among the various hormones and growth factors implicated, the minimal requirements for mammary epithelial cell proliferation are estrogen, progesterone and prolactin or growth hormone. Ligand binding and immunohistochemical analysis have detected ERs in both the epithelial and stromal compartments of the mouse mammary gland (Fendrick et al. 1998). Administration of estradiol (E2) to ovariectomized adult mice leads to an increase in DNA synthesis in the mammary epithelial cells (Imagawa et al. 1990). The site of the mitotic activity resides almost exclusively in the terminal end buds that result in ductal growth (Bresciani 1968, Daniel \& Silberstein 1987). In addition, it has been shown that estrogen acts locally to increase PR in the adult mammary epithelium (Haslam 1988). In prepubertal mice that are still undergoing ductal growth, anti-estrogen treatment leads to inhibition of DNA synthesis in the epithelial cells of the end buds (Silberstein et al. 1994), resulting in reduced ductal growth - that is, similar to the effects of ovariectomy. Estrogen treatment, however, does not lead to the development of the alveolar structures. These data 
establish the primary importance of estrogen in promoting ductal growth during puberty and that the end buds are the primary site of estrogen action. The biological effects of estrogens are mediated through ERs, and the detection of $E R \alpha$ in both ductal epithelial cells and stromal cells provides additional support for the action of estrogen on mammary gland development (Daniel \& Silberstein 1987). However, the effect of E2 on ductal growth is mediated via stromal $\mathrm{ER} \alpha$. This paracrine action of E2 has been verified through use of ER $\alpha$ knockout $(\alpha$ ERKO) mice, as discussed below.

Mammary glands from $\alpha$ ERKO mice are undeveloped, possessing only rudimentary ductal structures and lacking terminal end buds or alveolar development (Bocchinfuso \& Korach 1997). The fact that rudimentary aERKO mammary glands are present in adulthood indicates that embryonic development of the mammary gland is independent of $\mathrm{ER} \alpha$ signaling in the mouse. The lack of ductal outgrowth in pubertal $\alpha$ ERKO mice could result from an absence of $\mathrm{ER} \alpha$ function in the stromal cells, epithelium, or both. The tissue requirement of ER $\alpha$ was demonstrated by the construction of the four possible tissue recombinants composed of epithelium (E) and stroma (S) from neonatal wild-type and knockout (KO) mice: $\quad$ wt-S + wt-S, wt-S $+\alpha$ ERKO-E, $\quad \alpha$ ERKO$\mathrm{S}+\alpha$ ERKO-E, and $\alpha \mathrm{ERKO}-\mathrm{S}+\mathrm{wt}-\mathrm{E}$ (Cunha et al. 1997). All tissue recombinants were grown as subrenal capsule grafts in nude mice. Impaired ductal growth was observed when $\alpha$ ERKO fat pad was used as the recipient stroma $(\alpha$ ERKO-S $+\alpha$ ERKO-E and $\alpha$ ERKO-S $+w t-E)$. Extensive ductal growth occurred when wild-type fat pad was used (wt-S $+w t-E$ and wt-S $+\alpha E R K O-E$ ). These studies demonstrated that the hormonal regulation of ductal growth is a paracrine event mediated by $\mathrm{ER} \alpha$ positive stromal cells. In the adult, it appears that the ER requirement becomes altered in adulthood, because when mammary epithelial cells isolated from $\alpha$ ERKO adult mice or from wild-type counterparts were injected into epithelial-free mammary fat pads of 3-week-old female $\alpha \mathrm{ERKO}$ or wild-type mice it was found that both stromal and epithelial ER $\alpha$ were required for maximum mammary gland development in adult mice (Mueller et al. 2002). Presumably, E-mediated ductal morphogenesis and alveolar development may involve induction of estrogenresponsive genes within the mammary gland and in peripheral endocrine tissues that contribute to mammary gland development and function. (It may also be mentioned that mammary ductal growth is normal in $\mathrm{E}$ knockout mice (Krege et al. 1998)).

Estrogen-dependent stromal effects on mammary epithelium have been studied in vitro using minimally supplemented serum-free medium in a collagen gel primary mammary co-culture system (Zhang et al.
2002). Conditioned medium from mammary fibroblasts or co-culture of mammary gland epithelium with mammary fibroblasts caused increased epithelial cell proliferation and produced a tubular/ductal morphology. Hepatocyte growth factor (HGF) was identified as the mediator of this effect, because the proliferative activity in fibroblast-conditioned medium was completely abolished by a neutralizing antibody to HGF. In contrast, neutralizing antibodies to either epidermal growth factor or insulin-like growth factor-I had no effect. Treatment of mammary fibroblasts with estrogen increased the production of HGF. Thus estrogen may indirectly mediate mammary epithelial cell proliferation via the regulation of HGF in mammary stromal cells, and HGF has a vital role in estrogen-induced proliferation in vivo.

\section{Progesterone}

The action of progesterone is mediated through the PR. PRs have been detected by ligand binding studies using $\left[{ }^{3} \mathrm{H}\right] \mathrm{R} 5020$ in cytoplasmic extracts of intact mammary gland and in extracts of cleared murine fat pads devoid of epithelium containing only mammary adipose and connective tissues (Haslam \& Shyamala 1981), even though most of the binding sites for progesterone in the mammary gland are located in the glandular epithelium. Modulation of PR concentration during mammary gland development, in addition to the estrogen induction of PR, appear to be restricted to the epithelial component of the mammary gland. Immunohistochemical analysis showed that PR-positive cells were detected only in the epithelial cells of the ducts and in the fibrous mammary capsule, and were not observed in the adipose or fibrous stroma surrounding the ducts (Shyamala et al. 1997).

When progesterone is administered to ovariectomized adult mice, there is an increase in DNA synthesis in mammary epithelial cells, in end buds and ducts (Bresciani 1968, Shyamala 1997). If estrogen is administered with progesterone to ovariectomized adult mice, the level of DNA synthesis in mammary epithelial cells is greater than that seen with either steroid alone. The growth elicited in response to estrogen plus progesterone is characterized by outgrowth from terminal and lateral buds. The extent of ductal growth is dependent on the duration of exposure to the two steroids; prolonged administration of estrogen and progesterone (21-24 days) results in development of the mammary gland equivalent to that seen during early pregnancy, characterized by full lobuloalveolar development (Ichinose \& Nandi 1966), and with both the ductal and alveolar epithelium engaged in DNA synthesis (Bresciani 1968).

To define the role of progesterone in the proliferation and differentiation of the murine mammary gland, a 
progesterone receptor knockout (PRKO) mouse was generated (Lydon et al. 1995). Mammary ductal whole mounts of ovariectomized PRKO females treated with exogenous E2 and progesterone $(\mathrm{E} 2+\mathrm{P})$ showed normal ductal development, but an absence of characteristic ductal-alveolar morphogenesis. These studies demonstrated a proliferative role in addition to a differentiative role for progesterone in the mammary gland. To establish whether this action is mediated through PR of the epithelium or the stroma, transplantation studies were carried out using the PRKO and wild-type mammary glands. When ductal fragments were removed from 10week-old mature virgin PRKO donors and transplanted into the cleared fat pads of 3-week-old wild-type $(\mathrm{PR}+/+)$ or PRKO mice, the PRKO epithelium transplanted into either PRKO or PR $+/+$ fat pads formed normal appearing ductal structures after 8 weeks (Humphreys et al. 1997). However, estrogen and progesterone treatment failed to stimulate alveolar development in PRKO epithelium, whether transplanted into $\mathrm{PR}+/+$ or PRKO fat pads. These data demonstrate that direct epithelial PR signaling is necessary for alveolar development.

Other investigators also transplanted PRKO mammary gland epithelium into the fat pad of wild-type mice (Brisken et al. 1998). These studies have confirmed that the development of the mammary gland in the absence of epithelial PR is arrested at the stage of the simple ductal system found in the young virgin mouse. As described above, $\mathrm{PR}+/+$ mammary ducts transplanted into PRKO stroma gave rise to normal alveolar growth, whereas transplants containing PRKO epithelium did not develop alveoli in response to progesterone plus E2. However, when a chimeric epithelium containing PRKO plus $\mathrm{PR}+/+$ epithelial cells was transplanted into wild-type fat pads, the PRKO epithelial cells located near PR $+/+$ epithelial cells underwent complete alveolar development (Brisken et al. 1998). This indicates that progesterone acts by a juxtacrine mechanism in the mammary gland. In this regard, it has been recognized for many years that $P R$ is expressed in only a subset of mammary epithelial cells. Given the results of the experiments with the chimeric $\mathrm{PR}+/+$ and PRKO mammary epithelium, it is evident that action of progesterone on $\mathrm{PR}+/+$ epithelium elicits juxtacrine signals that can induce a 'progesterone response' (alveolar development) in adjacent epithelial cells genetically devoid of PR.

\section{Growth factors as mediators of hormonal action}

During pre- and postnatal development of the mammary gland, complex interactions occur between mammary epithelium, the fibrous mammary mesenchyme and the mammary fat pad (Ulich et al. 1994, Soriano et al. 1998). A number of growth factors have been implicated as autocrine and paracrine mediators of epithelial-mesenchymal interactions in the mammary gland: $\mathrm{HGF} /$ scatter factor (Niranjan et al. 1995, Yang et al. 1995, Soriano et al. 1998), keratinocyte growth factor (Ulich et al. 1994), transforming growth factor (TGF)- $\beta$ (Daniel \& Robinson 1992) and neuregulin (Yang et al. 1995) have been identified as factors that are produced by mesenchyme and thus may mediate short-range signals influencing mammary epithelial growth.

Ligands of the epidermal growth factor receptor (EGFR) are believed to be particularly important downstream mediators of steroid hormone action in the mammary gland, acting locally to regulate mammary gland growth and development via stromal-epithelial interactions. Mice lacking functional EGF, TGF- $\alpha$, or amphiregulin have been constructed and have revealed compensatory roles for these EGF-family ligands. The most profound defect, resulting in stunted ductal outgrowth during puberty, has been seen in amphiregulin knockout mammary glands (Luetteke et al. 1999).

EGFR, a member of the ErbB/type 1 family of receptor tyrosine kinases, can form homodimers or heterodimers with the other family members: ErbB2, ErbB3 and ErbB4 (Earp et al. 1995). In the mouse mammary gland, the EGFR is expressed in the stromal cells surrounding the terminal end buds, cap cells of end buds, adipocytes, myoepithelial cells and luminal epithelial cells (Coleman et al. 1988, Coleman \& Daniel 1990, DiAugustine et al. 1997). The requirement for EGFR in mammary gland development was established by using mice in which EGFR was inactivated (Miettinen et al. 1995). As EGFR-/- (EGFR-KO) mice die perinatally as a result of defects in pulmonary and gastrointestinal epithelia (Miettinen et al. 1995), the EGFR-KO mammary glands at postnatal days 1-3 have been grown as grafts under the renal capsule, but showed very little ductal development (Wiesen et al. 1999). To determine whether this defect is the result of the lack of EGFR signaling in the stroma or epithelium, wild-type or EGFR$\mathrm{KO}$ epithelium was transplanted into cleared fat pads of virgin female nude mice. Both EGFR-KO and wild-type epithelia undergo comparable ductal growth in virgin nude mouse hosts and comparable alveolar development in pituitary-grafted hosts. These findings suggest that epithelial EGFR is not required in the epithelium, but is required in the stroma. This was confirmed by preparing the four possible tissue recombinants composed of epithelium (E) and stroma (S) from wild-type and EGFR-KO mice. When wt-S was used (wt-S + wt-E and wt-S + EGFR-KO-E), ductal and alveolar growth 
were extensive. In contrast, when EGFR-KO stroma was used (EGFR-KO-S + EGFR-KO-E and EGFR-KO$\mathrm{S}+\mathrm{wt}-\mathrm{E})$, ductal growth was meager. Thus stromal EGFR appears to be required for ductal and alveolar growth (Wiesen et al. 1999).

TGF- $\beta 1$ is believed to act by autocrine or paracrine mechanisms to modulate cell division and extracellular matrix synthesis/deposition (Roberts \& Sporn 1990). There are high levels of TGF- $\beta$ transcripts in mammary epithelial tissues and lower levels of transcripts in fat cells and fibrous connective tissue stroma (Daniel \& Robinson 1992). There are three structurally related mammalian TGF- $\beta$ isoforms, TGF- $\beta 1,-\beta 2$ and $-\beta 3$, and all are expressed in the mouse mammary gland. By in situ hybridization, all three mRNAs exhibit overlapping patterns of expression within the epithelium of actively growing mammary end buds during branching morphogenesis (Robinson et al. 1991). Mature TGF- $\beta$ peptides are present in the stroma but not at the front of the advancing end buds, suggesting that a complex epithelialstromal interaction is involved in TGF- $\beta$ activation. TGF- $\beta 1$ administered from slow-release pellets causes end buds to regress during puberty, but does not inhibit lateral branching in adults or alveolar outgrowth necessary for secretory differentiation during pregnancy (Robinson et al. 1991, Daniel \& Robinson 1992). TGF$\beta 1$ knockout $(-/-)$ mice have been generated, but they die from gross inflammatory response at 3 weeks of age, thus precluding analysis of mammary maturation (Kulkarni et al. 1993). However as TGF- $\beta 1+/-$ mice are viable, mammary glands from this form were used for study. TGF- $\beta 1+$ and + epithelia were transplanted into wildtype $(+/+)$ mammary stroma. The outgrowth of TGF$\beta 1+/-$ epithelium was accelerated in wild-type fat pads, indicating that the TGF- $\beta 1$-deficient phenotype is intrinsic to the epithelium (Ewan et al. 2002).

Inhibins and activins are members of the TGF- $\beta$ superfamily (Thomas et al. 1998). Activins function as dimers of two $\beta$-subunits, $\beta A$ and $\beta B$. Three types of activins have been isolated: activin $A(\beta A \beta A)$, activin $B$ $(\beta B \beta B)$ and activin $\mathrm{AB}(\beta \mathrm{A} \beta \mathrm{B})$. Inhibins share a common $\alpha$ subunit associated with $\beta \mathrm{A}$ (inhibin $\mathrm{A}$ ) or $\beta \mathrm{B}$ (inhibin B). Inactivation of the activin/inhibin $\beta B$ gene results in impaired mammary development and failure of lactation: ductal elongation is incomplete, end buds persist throughout pregnancy and morphogenesis of secretory alveoli is reduced (Robinson \& Hennighausen 1997). The altered ductal architecture and the persistence of end buds reflect a perturbance in growth regulation, which results from lack of stimuli from the mammary stroma. Tissue transplant studies demonstrate that stromal-derived activin $\mathrm{B}$, activin $\mathrm{AB}$ or inhibin $\mathrm{B}$, or a combination of the three, are obligate for mammary ductal/alveolar development (Robinson \& Hennighausen 1997).

Parathyroid hormone-related protein (PTHrP) is expressed in the pregnant and lactating mammary gland and is detected in milk (Thiede \& Rodan 1988, Budayr et al. 1989). In the absence of PTHrP or the absence of PTH/ PTHrP receptor, mammary epithelial buds form, but fail to initiate the ductal branching morphogenesis exhibited by the relevant transgenic mouse models (Wysolmerski et al. 1998). Instead, the fetal mammary bud cells degenerate, and mammary glands do not form. Overexpression of PTHrP or PTH within the mammary gland also perturbs ductal branching morphogenesis by causing defects in ductal proliferation and side branching during puberty and inhibition of terminal ductule formation during early pregnancy (Wysolmerski et al. 1995). In this case, an excess of PTHrP results in severe defects in ductal proliferation and side branching during puberty and the inhibition of terminal ductule formation during early pregnancy. Hence, PTHrP, acting through its receptor, contributes to the regulation of ductal branching morphogenesis at several different stages of mammary development. During periods of active ductal morphogenesis, PTHrP and the $\mathrm{PTH} / \mathrm{PTHrP}$ receptor are localized in epithelial and mesenchymal cells respectively. During embryogenesis, puberty and during early to midpregnancy, PTHrP is expressed in mammary epithelial cells and the $\mathrm{PTH} / \mathrm{PTHrP}$ receptor is expressed in mammary stromal cells (Dunbar et al. 1998). To test whether the action of PTHrP is mediated through the epithelium or the stroma, mammary gland rudiments were dissected from E13 PTH/PTHrP knockout and wild-type embryos, and tissue recombinations were prepared with MGE and MGM: wt-MGM + wt-MGE, wtMGM + MGE-KO, MGM-KO + MGE-KO, and MGM-KO + wt-MGE. The tissue recombinants were transplanted under the renal capsule of female athymic nude mouse hosts and grown for 1 month. Results demonstrated that stromal PTHrP is necessary for normal development of the mammary gland (Dunbar et al. 1998). Mammary mesenchyme cells require functional PTHrP signaling for the cells to support the survival and outgrowth of embryonic mammary epithelial cells.

Lactogenic hormones have a major role in mammary gland function. These hormones regulate side branching and alveolar budding and elicit differentiation of milkproducing luminal epithelial cells. Concentrations of lactogenic hormones fluctuate during the estrous cycle, but particularly high hormonal concentrations are achieved during pregnancy (Nandi 1958). Hormones required for development of lobuloalveolar structures and milk synthesis during pregnancy include E2, glucocorticoids, growth hormone, progesterone and placental 
lactogen or prolactin, or both (Nandi 1958, McManaman \& Neville 2003).

Given the importance of prolactin and placental lactogens during the lactogenic phase of mammary differentiation, prolactin knockout (PRL-KO) and prolactin receptor knockout (PRLR-KO) mice have been created for the study of mammary growth and differentiation. Virgin mammary glands of mature wild-type, PRL-KO or PRLR-KO mice are virtually identical. Thus ductal growth is not compromised in the absence of a prolactin stimulus (Horseman et al. 1997, Ormandy et al. 1997). However, lobuloalveolar development and milk production are greatly impaired in PRL-KO and PRLR$\mathrm{KO}$ mice, which demonstrates a requirement for prolactin signaling in the functional differentiation of the mammary gland. Transplantation studies have verified that it is the prolactin signaling system in the epithelium that is critical. When PRLR-KO mammary epithelium was transplanted into wild-type mammary fat pads, normal ductal development occurred. Under the influence of pregnancy hormones, the PRLR-KO epithelium transplants showed some side branching, but lobuloalveolar development was not observed (Ormandy et al. 1997).

\section{Development of the human mammary gland}

Thus far, the mouse mammary gland has been the main focus of this review, but to understand tissue interactions in the human breast and extend insight from mouse studies, one must be aware of the differences between the mouse and human mammary glands. The first visible indication of human mammary gland development can be found during day 35 (4th week), with the proliferation of paired areas of epithelial cells in the epidermis of the thoracic region. Subsequently, these areas of proliferation extend in a line between the fetal axilla and inguinal region and form two indistinct ridges called the mammary ridges or milk streaks. By the end of week 6, the mammary ridges have regressed back to two areas in the thoracic region, where two solid epithelial masses (the mammary buds) begin to grow downwards into the underlying mesenchyme (Fig. 6). This solid core of cells continues to evaginate into the underlying mesenchyme and becomes surrounded by a more cellular zone of fibroblast-like cells within a dense collagenous stroma. The 9th week is the cone stage, at which there is further inward growth of the mammary placode. Between the 10 th and 12th weeks, called the budding stage, epithelial buds sprout from the invading placode, and the buds become lobular in shape, with notching (indentation) of the epithelial-stromal border. In the epidermis overlying the developing gland, the nipple begins to form. During
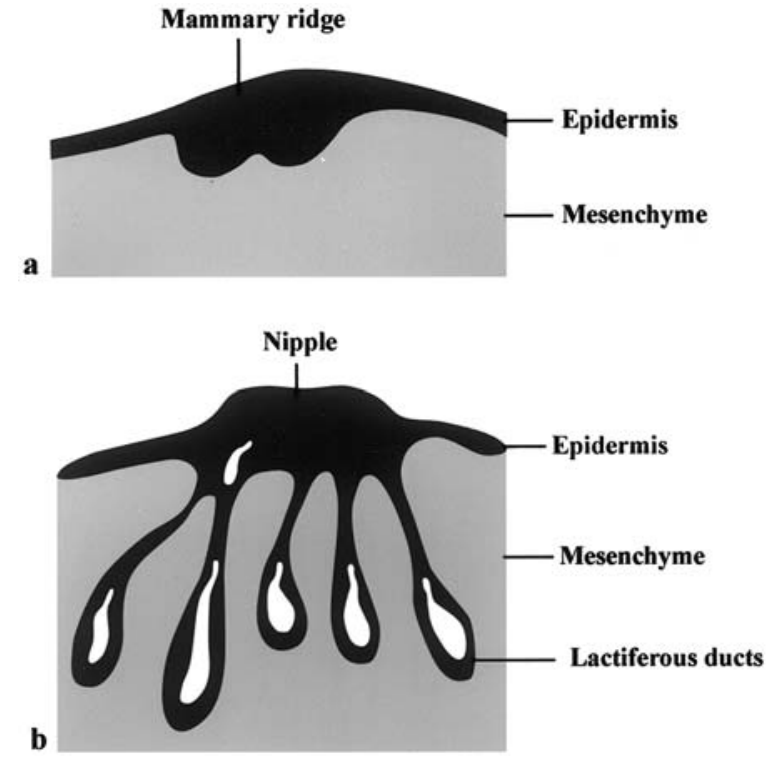

Figure 6 Schematic drawing of embryonic human breast development. (a) Early epidermal mammary ridge. (b) From the mammary ridge, solid epithelial sprouts grow into underlying mesenchyme to form lactiferous ducts. (Adapted from RonnovJessen et al. 1996, with permission.)

the same period, the mesenchymal cells differentiate into fibroblasts, smooth muscle cells, capillary endothelial cells and adipocytes. Further branching into 15-25 solid epithelial cords marks the branching stage at 15 weeks. Around week 20, the solid mammary cords canalize, and the epidermis in the region of the nipple becomes depressed, forming the mammary pit. The epithelial cells lining the ducts first appear as a bilayer of cuboidal cells. The luminal layer rapidly acquires the characteristics of secretory cells, whereas the basal layer becomes myoepithelial. By 6 months of gestation, the basic tubular architecture of the fetal gland has become established. The ducts are separated by 'fat islands' within a fibrous connective tissue stroma, and the rudimentary secretory epithelial cells become functional near the end of gestation in response to the lactogenic hormones of pregnancy. In contrast to rodent development, in which testosterone induces destruction of the mammary bud via condensation of the mesenchyme around the neck of the gland at E14 (Kratochwil \& Schwartz 1976), glands develop similarly in both the female and male human fetuses (Howard \& Gusterson 2000). After birth, the mammary gland becomes quiescent until the onset of puberty in girls, when it resumes growth of both the glandular tissue and the surrounding stroma. The ducts elongate, branch and form club-shaped terminal end buds, as seen in the mouse. The terminal end buds give rise to new branches and small ducts or alveolar buds. At puberty, changes 

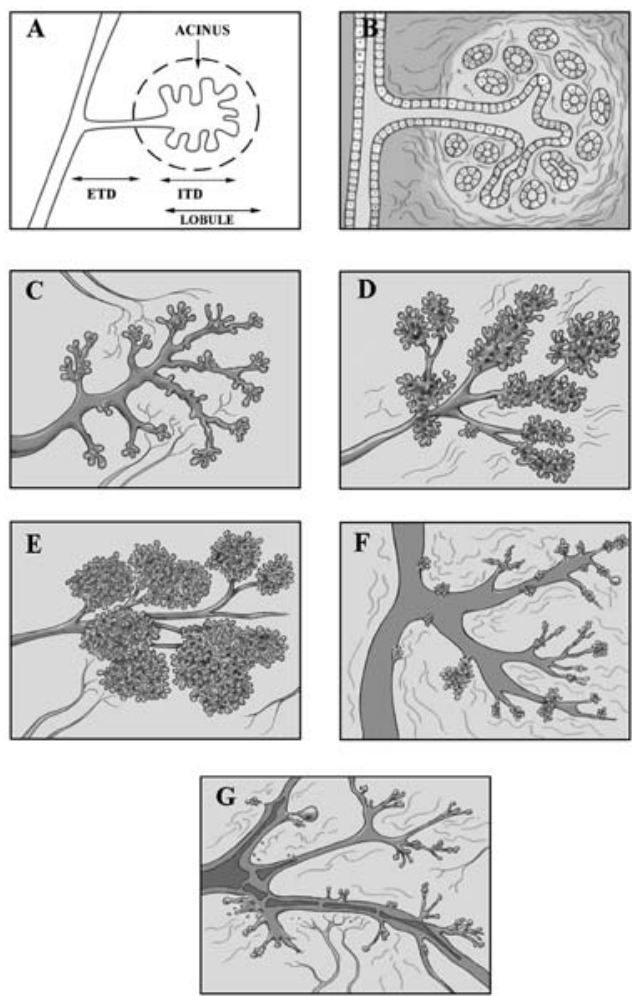

Figure 7 Drawings depicting the functional development of the human breast, the basic functional unit of which is the terminal ductal-lobular unit (TDLU). (A) Diagram of a TDLU emerging from the extralobular terminal duct (ETD). (B) Diagram depicting the histology of a normal TDLU in the resting nulliparous state, showing the terminal duct and associated acini. (C) Drawing of terminal branching structures from a 15year-old human breast. An extralobular duct is shown with rudimentary terminal branching structures. True lobules and acini are not yet present. (D) Drawing of TDLUs from a 22-yearold nulliparous human mammary gland having well developed lobules and acini. (E) Drawing of breast structures of a 30-yearold pregnant woman. Note well developed TDLUs. (F) Drawing of breast tissue of a 55-year-old parous menopausal woman. Ducts are dilated, and the TDLUs are atrophied. (G) Drawing of breast tissue of a 80-year-old woman. Marked atrophy of ducts and TDLUs can be seen.

occur in both the epithelium and stroma. In the stroma, there is an increase in the amount of fibrous and fatty tissue, with the adult non-lactating breast consisting of $80 \%$ or more of stroma. The extension of ducts in the pubertal human breast is preceded by proliferation of connective tissue; fatty tissue is believed to inhibit growth of human breast epithelium. The primary ducts emerging from the nipple give rise to a complex branching pattern of subsidiary ducts that leads to the so-called segmental ducts and to smaller subsegmental ducts (Howard \& Gusterson 2000). The subsegmental ducts lead to terminal ducts that give rise to blind-ended ductules called acini. A collection of acini arising from one terminal duct and embedded in intralobular stroma is referred to as a terminal ductal lobular unit (Figs 1A, 2A, B), which is considered the functional unit of the breast (Fig. 7). The lobules have been classified as types 1,2 and 3 lobules (Russo \& Russo 1987). In type 1 (virginal lobule), alveolar buds cluster around a terminal duct. Terminal ducts or alveolar buds are lined by a bi-layered epithelium, whereas four layers of epithelial cells line terminal end buds. The transition from lobule type 1 to type 2 to type 3 is a gradual process of sprouting of new alveolar buds. In type 2 and type 3 lobules, ductules increase in number from about 11 per type 1 lobule to 47 and 80 ductules per type 2 and type 3 lobules respectively. Type 1 lobules are mainly found in the breast of nulliparous young women, whereas lobules type 2 and type 3 are more frequent in the gland of parous women. Type 4 lobules are the maximal expression of development and differentiation in the adult gland, seen in pregnancy when glands are secreting milk and have undergone complete functional differentiation (Fig. 7).

\section{Human mammary cells in culture: in vitro studies of human epithelial-stromal interactions}

The establishment of human breast epithelial cell cultures that replicate and retain their original characteristics has proven extraordinarily difficult, despite the development of a number of different strategies for epithelial cell isolation and culture. Models used to grow human breast epithelium include organ culture, mammary epithelial cell culture and mammary epithelial cell-stromal co-culture. Organ culture methods have the advantage that the normal glandular architecture remains intact, and such organ cultures can undergo lobuloalveolar development, express milk proteins in a hormone-dependent manner, and undergo involution after hormonal withdrawal. Culture of isolated mammary epithelial cell organoids within an Engelbreth-Holm-Swarm murine tumor-derived reconstituted basement membrane permits (a) formation of spherical, polarized structures that resemble normal mammary alveoli (or acini), (b) ductal branching, (c) alveolar morphogenesis and (d) accumulation of milk protein and lipid in a physiologically relevant hormoneand growth factor-dependent manner (Barcellos-Hoff et al. 1989). This model can thus be utilized to investigate the mechanism by which various modulators exert direct effects on the epithelium (reviewed by Schmeichel \& Bissell 2003). However, using this system does not enable study of epithelial-stromal interactions, as only epithelial cells are used in conjunction with the basement membrane. Human mammary epithelial cells have also been 
cultured in collagen gels (Yang et al. 1980). Such conditions lead to a 10 - to 30 -fold increase in cell numbers, and this growth is maintained even after passage to secondary culture. Thus the collagen gel system provides a reproducible and consistent method for sustained three-dimensional growth of mammary epithelial cells from human breast tissue in culture.

To study the epithelial-stromal interactions, human mammary epithelial cells have been co-cultured with enriched populations of stromal cells. Reproduction of the complete tissue environment in culture models enables the normal epithelial-stromal interactions to be studied in vitro. Fibroblasts or fibroblast-derived conditioned medium have been shown to stimulate the growth of primary human epithelial cells; however, the mitogenic response was dependent on serum, direct contact between the epithelial and stromal cells, estrogen, or combinations thereof (Taylor et al. 1977, McGrath 1983).

\section{Human breast xenografts in nude mice: studying human breast epithelial-stromal interactions in vivo}

Elucidation of the role of hormones in the growth and differentiation of the mammary gland has largely been achieved using the rodent as the experimental model. However, as described, the mouse and human mammary glands differ considerably, particularly in regard to the nature of the stroma, which is mostly adipose in the mouse but primarily fibroblastic in the human. Study of stromal-epithelial interactions in the human mammary gland has proven difficult, but with increasing understanding, better in vivo models have evolved.

Outzen \& Custer (1975) transplanted pieces of normal human breast into cleared fat pads of athymic nude mice and reported that the tissue produced outgrowths that proliferated into the mouse mammary fat pads. In contrast, when Jensen \& Wellings (1976) repeated this experiment, they did not observe growth of transplanted normal human breast tissue into the mouse mammary fat pad. McManus \& Welsch $(1981,1984)$ also transplanted normal human breast tissue into nude mice. In these experiments, small pieces of tissue taken from the periphery of benign breast lesions were implanted subcutaneously into intact female athymic nude mice. Growth of the ductal epithelium within the human breast transplants, as a function of the hormone treatment, was assessed by the number of $\left[{ }^{3} \mathrm{H}\right]$ thymidine-radiolabeled ductal cells per unit area of ductal epithelium (the labeling index). The administration of estrogen or thyroxine alone significantly increased the labeling index, but treatment with progesterone or human placental lactogen (HPL) alone did not substantially influence it. HPL treatment, but not progesterone or thyroxine treatments, significantly enhanced the stimulatory effect of estrogen on the labeling index. In these experiments, in which normal breast architecture was maintained, the epithelium maintained its normal differentiation and was able to proliferate in response to hormones (McManus \& Welsch 1984). When the epithelial component and the stromal component were present, mammotrophic hormones (estrogen or thyroxine) induced proliferation. Attempts to exploit the mouse cleared fat pad technology lead to the transplantation of enzymatically isolated human breast ductal organoids into cleared mammary fat pads of athymic nude mice, in the hope that ductal outgrowth would occur (Gusterson et al. 1984, Dubois et al. 1987, Sheffield \& Welsch 1988). For the most part, the findings of these studies have been disappointing. Human ductal organoids digested free of both interlobular and intralobular stroma typically formed small nodules in the mouse fat pad, and ducts never extended to 'fill' the fat pad (Gusterson et al. 1984). Despite the minimal ductal outgrowth, luminal and myoepithelial cells maintained their normal differentiation. Proliferative and lactogenic responses to the hormones of pregnancy were reported in organoids transplanted into the mammary fat pad or into sacral sites, even though ductal outgrowths were not observed after 28 days in vivo (Dubois et al. 1987). Similar results were also observed when bovine mammary epithelial cells were transplanted into mammary fat pads of the athymic nude mouse. Bovine mammary organoids maintained their normal differentiation, and after administration of an intense mammotrophic hormonal stimulus to the host the size of the organoids increased significantly, but evidence of expansive ductal growth of these structures was never observed (Sheffield \& Welsch 1986). In contrast, when rat or mouse mammary epithelial cells were transplanted to the gland-free fat pad of the athymic nude mouse, the epithelial cells organized into branched ductal structures that grew to fill the fat pad completely (Welsch et al. 1987). On administration of a hormonal stimulus (prolactin or ovarian steroids, or both) to the host mouse, intense and expansive alveolar growth of the rat or mouse ductal epithelium was observed. These data suggest that the mouse fat pad may not be a suitable environment for development of human mammary epithelium and may not allow for robust ductal development as seen when mouse or rat epithelium is transplanted into the nude mouse mammary fat pad. Bearing in mind the morphology of the normal mouse mammary gland compared with that of the human, and the epithelialstromal interactions required for mammary development in both species, the lack of human breast epithelial development in the mouse fat pad may be attributable to the lack of an appropriate stromal environment, suggesting 


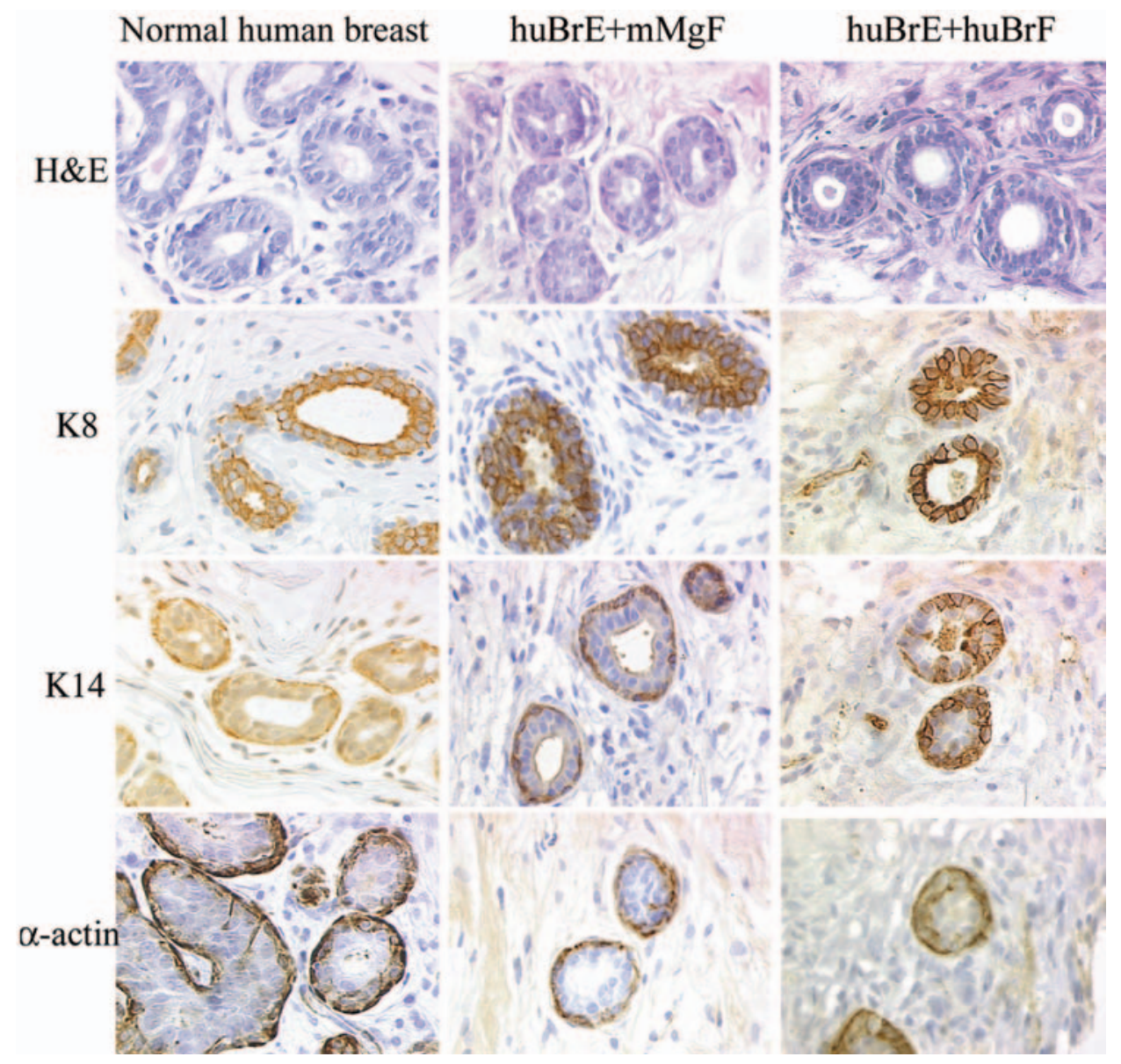

Figure 8 Histology and expression of markers of differentiation in human mammary ducts and ducts in huBrE $+\mathrm{mMgF}$ and huBrE + huBrF tissue recombinations grown for 1 month under the renal capsule of intact female athymic mice. Hematoxylin \& eosin (H\&E) staining of normal human breast tissue and ducts from huBrE $+\mathrm{mMgF}$ and huBrE + huBrF tissue recombinations all show the presence of ducts with lumens. Immunohistochemistry with markers of differentiation for luminal epithelial cells (keratin 8, K8), myoepithelial cells (keratin 14, K14), and smooth muscle actin ( $\alpha$-actin) reveals similar patterns of expression in ducts of normal human breast and ducts in the huBrE $+\mathrm{mMgF}$ and huBrE + huBrF tissue recombinations. All images are shown at $\times 400$ magnification.

species specificity in the stromal requirements for human as opposed to rodent mammary epithelium. As mentioned above, mouse mammary stroma is composed predominantly of fat with small amounts of interspersed fibrous tissue, whereas the human breast epithelium is typically associated with fibrous connective tissue (Haagensen 1971, Topper \& Freeman 1980). Thus lack of human epithelial growth in the mouse fat pad may be attributable to the lack of an appropriate fibrous connective tissue.

A group headed by Nandi developed a method for growing human breast epithelial cells that involved first embedding the human epithelial cells in collagen gels, which were in turn transplanted subcutaneously into athymic nude mice (Yang et al. 1994). The advantage is that, rather than epithelial cells being injected into the cleared fat pad, cells were grafted in collagen, which was known to support growth of human breast cells in vitro (Yang et al. 1980). Each collagen gel contained 10$30 \times 106$ epithelial cells. Such transplants of mammary epithelial cells develop normal ductal structures and retained their ability to express both the ER and PR in these experimental systems (Yang et al. 2000). At harvest, the human ductal structures were surrounded by stromal cells, presumably as a result of infiltration of mouse stromal cells from the graft site. Thus, in some sense, interaction of the human mammary epithelial cell with a fibroblastic stroma was re-established. Using this system, addition of $17 \beta-\mathrm{E} 2$ and progesterone in normal human physiologic doses did not elicit histomorphological changes in human mammary epithelium grown in collagen gels in vivo. Moreover, 17 $\beta$-E2 and progesterone in physiologic doses had little effect on the labeling index 


\section{A huBrE+mMgF}

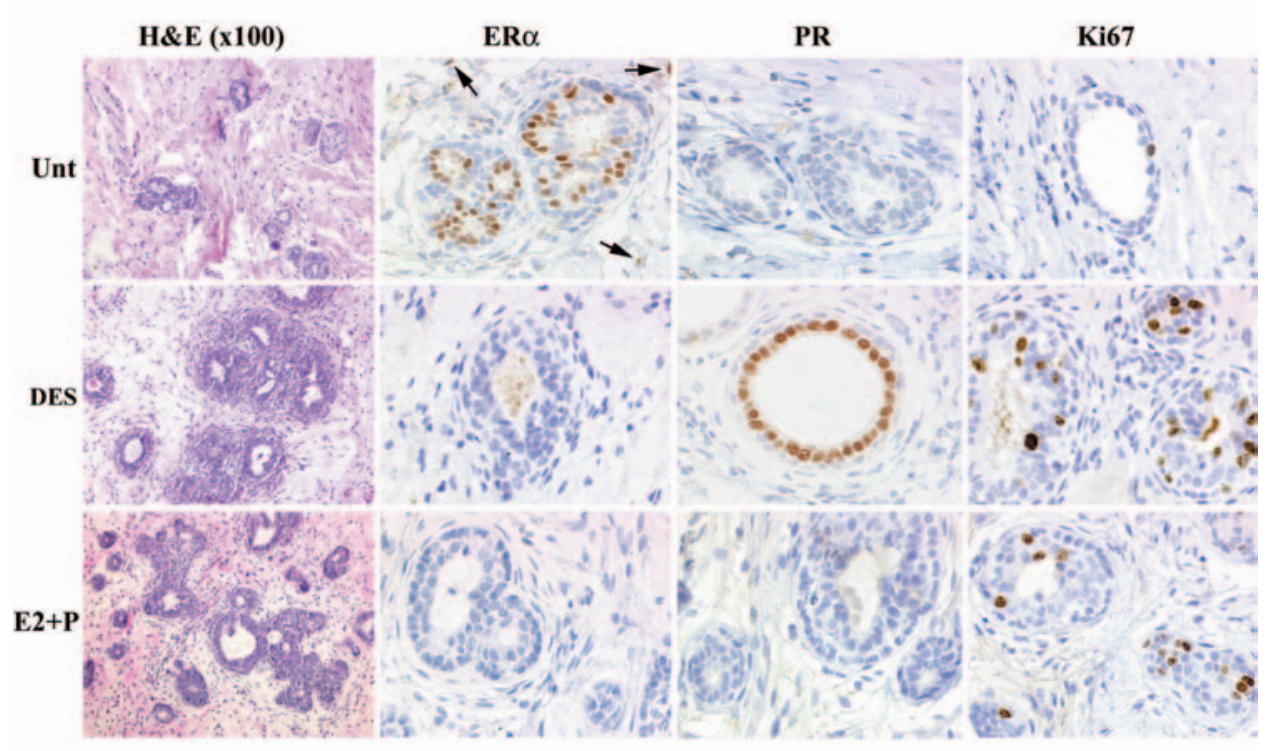

\section{B huBrE+huBrF}

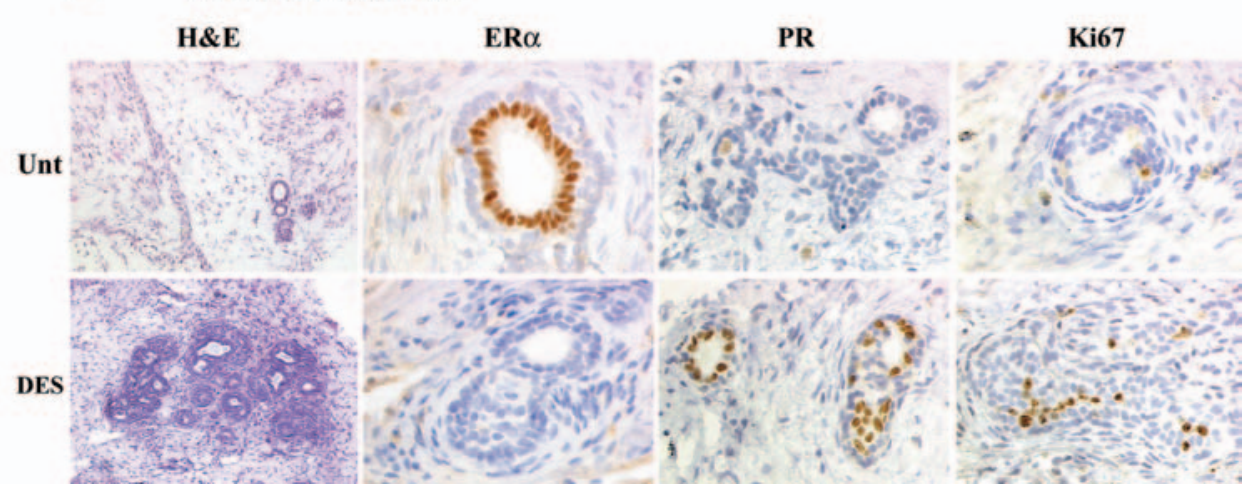

Figure 9 Hormonal and proliferation responses in huBrE $+\mathrm{mMgF}$ and huBrE + huBrF tissue recombinations. (A) Ducts from huBrE + mMgF increased in number after treatment with DES and E2 + P, as shown in hematoxylin \& eosin (H\&E) stained sections. Untreated grafts (Unt) are ER $\alpha$-positive and have very low concentrations of PR and few Ki67-positive cells. Treatment with DES for 1 month resulted in an increase in ductal density, downregulation of ER, and induction of PR. There was also an increase in the Ki67 labeling index. Treatment with E2 + P for 1 month resulted in an increase in ductal density and downregulation of ER; PR was undetectable. Increase in Ki67 epithelial labeling was similar to that observed with DES treatment alone. Arrows indicate ER $\alpha-$ positive fibroblasts in the stroma. (B) huBrE + huBrF tissue recombinations also showed an increase in ductal density after treatment with DES, as shown in (H\&E) stained sections. Ducts from untreated grafts (Unt) were Era-positive and had low levels of PR and Ki67-labeled cells. Treatment with DES pellet for 1 month resulted in an increase in the ductal density and downregulation of ER; PR was induced, and there was an increase in the Ki67 labeling index. H\&E stained sections are shown at $\times 100$ magnification; ER $\alpha$, PR and Ki67 are shown at $\times 400$ magnification.

of human mammary epithelial cells, even though mammary epithelial differentiation was well maintained in the collagen gel grafts. However, a pharmacologic dose of $17 \beta-E 2$ or a growth factor combination containing epidermal growth factor, cholera toxin and cortisol significantly stimulated the proliferation of the human mammary epithelial cells (Popnikolov et al. 1995). The effects of pregnancy of the host mouse were assessed in human breast epithelial cells transplanted into athymic nude mice, using cell proliferation as a measure of response (Popnikolov et al. 2001). Proliferation reached a maximum during late pregnancy before parturition; however, exposure to a second cycle of host mouse pregnancy did not result in a further increase in 
proliferation. The effect of human chorionic gonadotrophin (hCG) on transplanted human mammary epithelial cells was also tested. hCG alone stimulated proliferation of human cells in a dose-dependent manner, and was able to produce further enhancement of the stimulation achieved with estrogen; however, the effect of hCG on both human and mouse cells was dependent on intact ovaries, as the stimulation did not occur in ovariectomized animals (Popnikolov et al. 2001). Functional differentiation of the human breast epithelium under the influence of the mouse pregnancy hormones was not tested.

Although Nandi's model represented a clear advance for the field, we believed that improvements could be achieved by providing the human mammary epithelial cell with a fibrous stroma of collagen containing actual mammary fibroblasts. Accordingly, we reconstituted human mammary epithelial cells in association with a more appropriate 'mammary' stroma of collagen plus mammary fibroblasts, which we reasoned would more faithfully reconstitute normal epithelial-stromal interactions, thus facilitating epithelial growth, differentiation and hormonal response. Another improvement was the utilization of the renal capsule graft site, which provides one of the most vasculogenic sites for transplantation, thus resulting in a high take-rate and optimal growth. The renal capsule site has been used for growth of rat pancreatic islets (Reece-Smith et al. 1981), mouse neural lobes (Stach-Chilf et al. 1981), human gliomas (Weizsacker et al. 1983), human tumor xenografts (Aamdal et al. 1985), human fetal mammalian reproductive tract (Taguchi et al. 1984), mouse mammary glands (Wiesen et al. 1999) and a variety of other cells and tissues. Incorporating these modifications, a novel method was used to grow human breast epithelium in vivo, using organoids from reduction mammoplasties combined with either mouse or human mammary fibroblasts embedded in a collagen gel that was transplanted under the renal capsule of female nude mice (Parmar et al. 2002). The collagen gels $(20 \mu \mathrm{l})$ contained $\sim 50000$ human mammary epithelial cells and 250000 fibroblasts, vastly fewer cells than had been used by previous investigators. These technical modifications led to robust ductal growth as judged histologically. The human breast epithelial cells were arranged as ducts composed of a continuous layer of luminal cells surrounded by a discontinuous layer of myoepithelial cells, as is the case for normal human breast (Fig. 8). Immunohistochemistry was performed on the ducts of recombinants composed of human breast epithelial cells plus either mouse or human mammary fibroblast recombinations, and confirmed the presence of luminal epithelial cells using an antibody against keratin 8 . Myoepithelial cells expressed cytokeratin 14 and $\alpha$-smooth muscle actin (Fig. 8). ER $\alpha$ was expressed in the luminal epithelial cells at high concentrations in about $80 \%$ of the cells. PR was expressed at low concentrations in recombinants grown in untreated female hosts. Thus histodifferentiation of human breast epithelial cells was normal when they were grown in association with normal human or wild-type mouse mammary fibroblasts and was comparable to that of normal human breast tissue. The use of either human or mouse mammary fibroblasts led to the normal and robust ductal development of the human breast epithelial cells in vivo after 1 month under the renal capsule, although grafts produced using mouse mammary fibroblasts were larger and exhibited better growth of the human breast epithelial cells. Thus use of mouse mammary fibroblasts as the stromal environment allowed growth of human breast epithelium to take place in vivo.

Tissue recombinations prepared with human breast epithelial cells + human breast fibroblasts (huBrE + huBrF) or huBrE + mouse mammary gland fibroblasts $(\mathrm{mMgF})$ were treated for 30 days continuously with a diethylstilbestrol (DES) pellet. This treatment increased the number of ducts per microscopic field in huBrE $+\mathrm{mMgF}$ recombinants (Fig. 9A) and in huBrE + huBrF (Fig. 9B) recombinations. In untreated intact or ovariectomized hosts, an average of eight ducts per microscopic field was observed using a $\times 20$ objective, whereas an average of 11 ducts per microscopic field was observed in huBrE $+\mathrm{mMgF}$ recombinants treated with DES - a significant increase in ductal number (Fig. 10A). Ki67 epithelial labeling was higher in the ducts of huBrE $+\mathrm{mMgF}$ recombinants after addition of fibroblasts than after grafting the organoids alone in intact untreated hosts, suggesting that incorporation of mouse or human mammary fibroblasts into the collagen gel enhances the proliferation of huBrE cells. This effect on epithelial proliferation coincided with an increase in the number of ducts per microscopic field in grafts combined with mammary fibroblasts. The Ki67 labeling index was further increased twofold in huBrE $+\mathrm{mMgF}$ tissue recombinations grown in DES-treated hosts relative to that in grafts of organoids grown in hosts treated with DES alone. The huBrE + huBrF recombinations showed a similar increase in Ki67 labeling and ductal density after DES treatment (Fig. 10B). Treatment of hosts continuously with DES also caused a profound downregulation of epithelial ER $\alpha$. PR was induced by the DES treatment in the luminal epithelial cells of huBrE $+\mathrm{mMgF}$ and huBrE + huBrF recombinations (Fig. 9). Thus both mouse and human mammary fibroblasts provided a favorable stromal environment for the growth and differentiation of human mammary epithelium and facilitated estrogenic response. 


\section{$\mathbf{A}$}

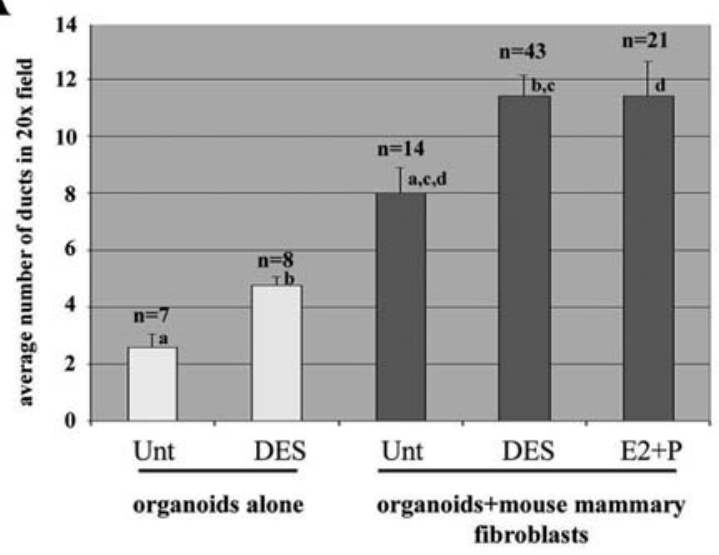

B

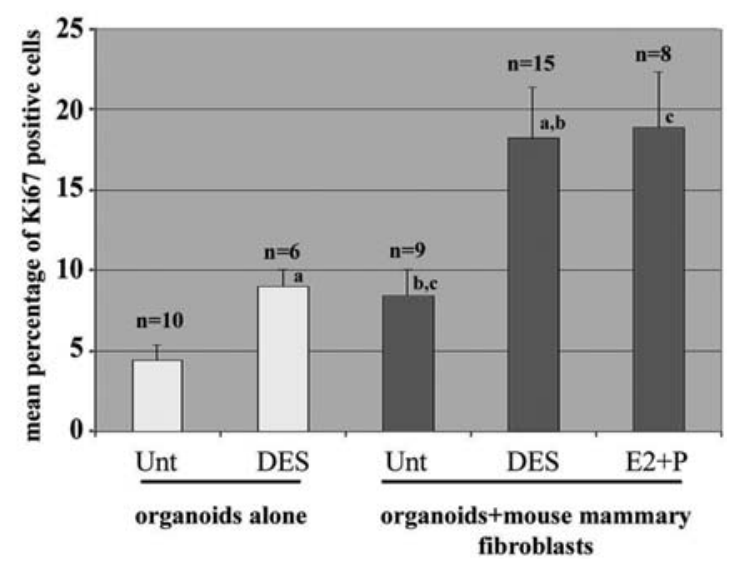

Figure 10 Comparison of ductal numbers and epithelial Ki67 labeling indexes in grafts of untreated (Unt) and hormone-treated organoids alone and in huBrE $+\mathrm{mMgF}$ tissue recombinations. (A) Comparison of ductal densities of untreated and hormone-treated grafts of organoids alone and of $\mathrm{huBrE}+\mathrm{mMgF}$ tissue recombinations. Observations were made with the aid of a $\times 20$ objective. (a) Untreated organoids when combined with fibroblasts showed a significant increase in ductal numbers $(P=0.0105)$; (b) DES treatment of organoids and mouse fibroblasts significantly increased ductal numbers relative to those in DES-treated organoids alone $(P=0.0002)$; (c) DES treatment of organoids and mouse fibroblast recombinations significantly increased ductal numbers relative to untreated values $(P=0.0152)$; (d) $\mathrm{E} 2+\mathrm{P}$ treatment of organoids and mouse fibroblast recombinations significantly increased ductal density relative to that in the untreated group $(P=0.0152)$. (B) Ki67 labeling index observed with the aid of a $\times 20$ objective. (a) DES-treated organoids and mouse fibroblasts significantly increased Ki67 relative to DES-treated organoids alone $(P=0.0257)$; (b) DES-treated organoids and mouse fibroblasts significantly increased the Ki67 index relative to that in the untreated group $(P=0.0075)$; (c) $\mathrm{E} 2+\mathrm{P}$ treatment of organoids and mouse fibroblasts significantly increased Ki67 labeling relative to that in the untreated group $(P=0.0132)$.

In $\mathrm{E} 2+\mathrm{P}$-treated hosts, epithelial ER $\alpha$ and PR were undetectable in huBrE $+\mathrm{mMgF}$ recombinants. Presumably, E2 induced epithelial PR, and then progesterone downregulated its own receptor. Time-course experiments will be required to examine this possibility. The epithelial Ki67 labeling index in the E2 + P-treated grafts increased more than twofold compared with that for untreated huBrE $+\mathrm{mMgF}$ and huBrE + huBrF tissue recombinations (Fig. 10B). In parallel, E2 $+\mathrm{P}$ increased ductal density to an average of 11 ducts per microscopic field, similar to that observed with DES alone (Fig. 10A). No significant increase in Ki67 or ductal density was achieved by combining progesterone with estrogen.

To elicit a lactogenic response in the grafts of huBrE + huBrF or huBrE $+\mathrm{mMgF}$, the host mice were mated 3 weeks after grafting. The grafts were removed at day 18 of gestation. The resulting ducts were distended with secretions, and the apical cytoplasm of luminal cells 


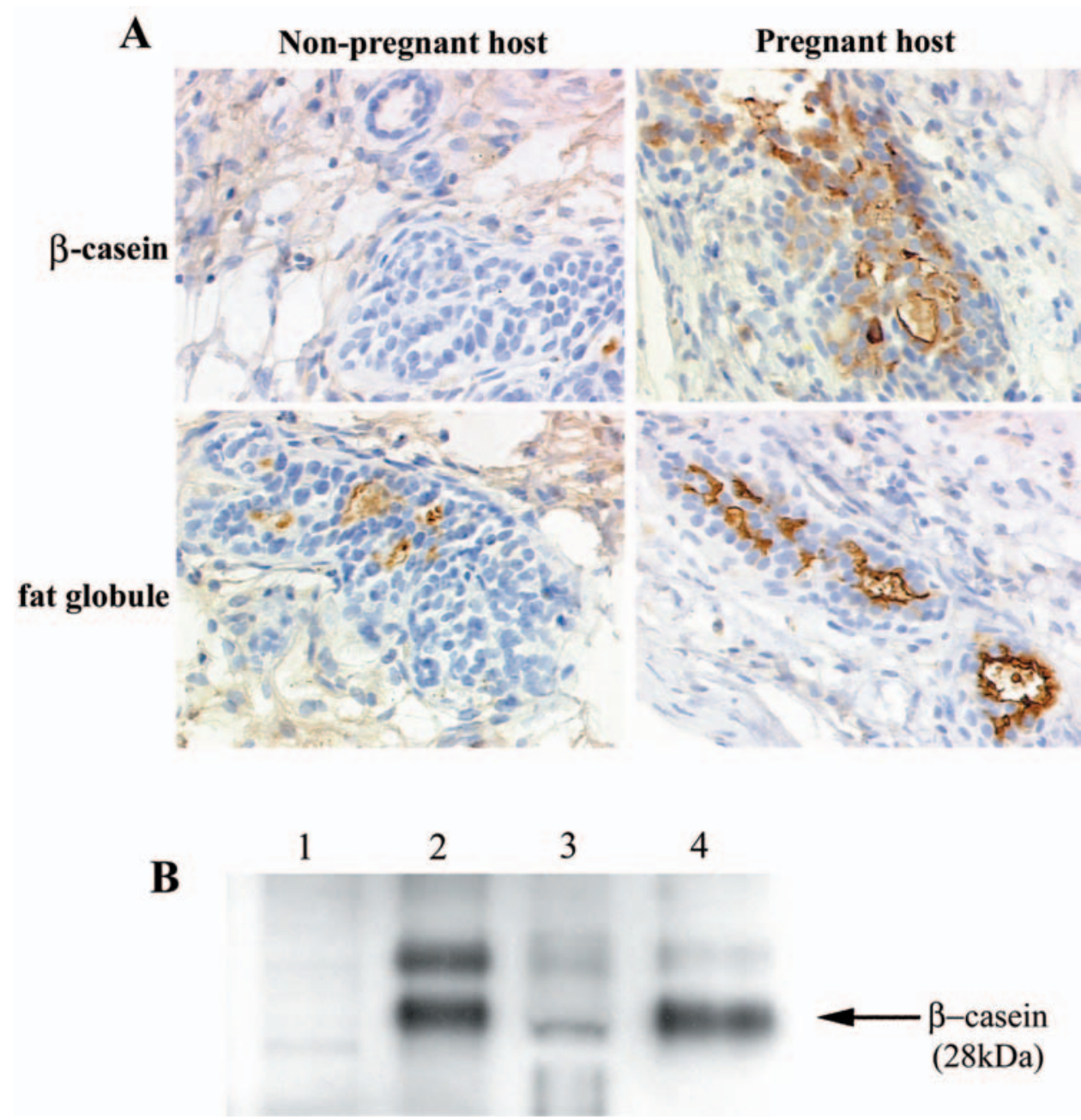

Figure 11 huBrE + mMgF recombinations undergo morphological change and functional differentiation in the pregnant host. (A) In untreated hosts, immunostaining for antihuman $\beta$-casein was undetectable, and milk fat globule protein expression was weak. In grafts harvested from an 18-day-pregnant host, $\beta$-casein and milk fat globule were strongly expressed. Magnification, $\times 400$.

(B) Western blot analysis of $\beta$-casein protein using a human-specific antibody showed an increase in huBrE $+\mathrm{mMgF}$ recombinations harvested from grafts grown in 18-day-pregnant hosts compared with grafts grown in non-pregnant hosts. Virgin mouse mammary gland (lane 1) did not express $\beta$-casein. Pregnant mouse mammary gland (lane 2) showed two bands, at 28 and $32 \mathrm{kDa}$.

$\mathrm{huBrE}+\mathrm{mMgF}$ recombination from virgin host (lane 3 ) showed very weak expression of $\beta$-casein, whereas in the huBrE $+\mathrm{mMgF}$ grown in a pregnant host, $\beta$-casein expression showed a strong band at $28 \mathrm{kDa}$ (lane 4 ).

was vacuolated (Fig. 11A). Confirmation of the lactation response was obtained using monoclonal antibodies against $\beta$-casein and the milk fat globule membrane protein antigen. The results showed an increase in the expression of $\beta$-casein and the fat globule protein compared with grafts harvested from non-pregnant hosts (Fig. 11B).

\section{Future perspectives}

Our collagen/fibroblast/human breast epithelial organoid model provides a very useful system for studying epithelial-stromal interactions using human mammary epithelium. The similarity in results obtained by the use of both human and mouse mammary fibroblasts in combination with huBrE demonstrates that processes in the human breast are sufficiently identical to those in the mouse that normal $\mathrm{mMgF}$ can substitute for human mammary stroma. Because wild-type mouse mammary fibroblasts facilitate or promote the growth and development of human breast epithelium, future studies can use mouse mammary fibroblasts derived from a variety of mutant or transgenic mice to assess the roles of various paracrine pathways in the growth, differentiation and 
hormone response of human breast epithelia. This can be used to investigate key questions in human mammary gland development, such as the requirement for stromal ERs or stromal PRs. Fibroblasts from mouse or human cancers can also be combined with human epithelium to test the effects of these abnormal stromal cells on the epithelium, as carcinoma-associated fibroblasts have been shown to promote progression to malignancy in a prostatic model (Olumi et al. 1999). The use of tumor fibroblasts or tumorigenic epithelium in this model will also facilitate the study of breast cancer.

\section{Acknowledgements}

We wish to thank Mike McLaughlin for drawing the figures. This work was supported by NIH grant CA91967.

\section{References}

Aamdal S, Fodstad O, Nesland JM \& Pihl A 1985 Characteristics of human tumour xenografts transplanted under the renal capsule of immunocompetent mice. British Journal of Cancer $51347-356$.

Asch HL \& Asch BB 1985 Expression of keratins and other cytoskeletal proteins in mouse mammary epithelium during the normal developmental cycle and primary culture. Developmental Biology 107 470-482.

Balinsky BI 1949 On the developmental processes in mammary glands and other epidermal structures. Transactions of the Royal Society, Edinburgh 62 1-31.

Barcellos-Hoff MH, Aggeler J, Ram TG \& Bissell MJ 1989 Functional differentiation and alveolar morphogenesis of primary mammary cultures on reconstituted basement membrane. Development 105 223-235.

Binart N, Ormandy CJ \& Kelly PA 2000 Mammary gland development and the prolactin receptor. Advances in Experimental Medicine and Biology 480 85-92.

Bocchinfuso WP \& Korach KS 1997 Mammary gland development and tumorigenesis in estrogen receptor knockout mice. Journal of Mammary Gland Biology and Neoplasia 2 323-334.

Bresciani F 1968 Topography of DNA synthesis in the mammary gland of the $\mathrm{C} 3 \mathrm{H}$ mouse and its control by ovarian hormones: An autoradiographic study. Cell and Tissue Kinetics 1 51-63.

Brisken C, Park S, Vass T, Lydon JP, O'Malley BW \& Weinberg RA 1998 A paracrine role for the epithelial progesterone receptor in mammary gland development. PNAS $\mathbf{9 5}$ 5076-5081.

Budayr AA, Halloran BP, King JC, Diep D, Nissenson RA \& Strewler GJ 1989 High levels of a parathyroid hormone-like protein in milk. PNAS 86 7183-7185.

Coleman S \& Daniel CW 1990 Inhibition of mouse mammary ductal morphogenesis and down-regulation of the EGF receptor by epidermal growth factor. Developmental Biology 137 425-433.
Coleman S, Silberstein G \& Daniel C 1988 Ductal morphogenesis in the mouse mammary gland: evidence supporting a role for epidermal growth factor. Developmental Biology 127 304-315.

Cunha GR \& Hom YH 1996 Role of mesenchymal-epithelial interactions in mammary gland development. Journal of Mammary Gland Biology and Neoplasia $121-35$.

Cunha GR, Young P, Christov K, Guzman R, Nandi S, Talamantes F \& Thordarson G 1995 Mammary phenotypic expression induced in epidermal cells by embryonic mammary mesenchyme. Acta Anatomica 152 195-204.

Cunha GR, Young P, Hom YK, Cooke PS, Taylor JA \& Lubahn DB 1997 Elucidation of a role of stromal steroid hormone receptors in mammary gland growth and development by tissue recombination experiments. Journal of Mammary Gland Biology and Neoplasia 2 393-402.

Daniel CW \& Robinson SD 1992 Regulation of mammary growth and function by TGF-beta. Molecular Reproduction and Development 32 145-151.

Daniel CW \& Silberstein GB 1987 Postnatal development of the rodent mammary gland. In The Mammary Gland Development, Regulation and Function, pp 3-36. Eds MC Neville \& CW Daniel. New York: Plenum Press.

De Ome KB, Faulkin LJ Jr \& Bern HA 1959 Development of mammary tumors from hyperplastic alveolar nodules transplanted into gland-free mammary fat pads of female C3H mice. Cancer Research 19 515-520.

DiAugustine RP, Richards RG \& Sebastian J 1997 EGF-related peptides and their receptors in mammary gland development. Journal of Mammary Gland Biology and Neoplasia 2 109-117.

Dubois JD, O'Hare MJ, Monaghan P, Bartek J, Norris R \& Gusterson BA 1987 Human breast epithelial xenografts: an immunocytochemical and ultrastructural study of differentiation and lactogenic response. Differentiation 35 $72-82$.

Dunbar ME, Young P, Zhang JP, McCaughern-Carucci J, Lanske B, Orloff JJ, Karaplis A, Cunha G \& Wysolmerski JJ 1998 Stromal cells are critical targets in the regulation of mammary ductal morphogenesis by parathyroid hormonerelated protein. Developmental Biology 203 75-89.

Dürnberger H \& Kratochwil K 1980 Specificity of tissue interaction and origin of mesenchymal cells in the androgen response of the embryonic mammary gland. Cell 19 465-471.

Earp HS, Dawson TL, Li X \& Yu H 1995 Heterodimerization and functional interaction between EGF receptor family members: a new signaling paradigm with implications for breast cancer research. Breast Cancer Research Treat 35 $115-132$.

Ewan KB, Shyamala G, Ravani SA, Tang Y, Akhurst R, Wakefield L \& Barcellos-Hoff MH 2002 Latent transforming growth factor-beta activation in mammary gland: regulation by ovarian hormones affects ductal and alveolar proliferation. American Journal of Pathology 160 2081-2093.

Fendrick JL, Raafat AM \& Haslam SZ 1998 Mammary gland growth and development from the postnatal period to postmenopause: ovarian steroid receptor ontogeny and regulation in the mouse. Journal of Mammary Gland Biology and Neoplasia 3 7-22.

van Genderen C, Okamura RM, Farinas I, Quo RG, Parslow TG, Bruhn L \& Grosschedl R 1994 Development of several 
organs that require inductive epithelial-mesenchymal interactions is impaired in LEF-1-deficient mice. Genes and Development 8 2691-2703.

Gusterson BA, Williams J, Bunnage H, O'Hare MJ \& Dubois JD 1984 Human breast epithelium transplanted into nude mice. Proliferation and milk protein production in response to pregnancy. Virchows Archiv. A, Pathological Anatomy and Histopathology (Berlin) 404 325-333.

Haagensen CD 1971 The physiology of the breast as it concerns the clinician. American Journal of Obstetrics and Gynecology 109 206-209.

Haslam SZ 1988 Progesterone effects on deoxyribonucleic acid synthesis in normal mouse mammary glands. Endocrinology 122 464-470.

Haslam SZ \& Shyamala G 1981 Relative distribution of estrogen and progesterone receptors among the epithelial, adipose, and connective tissue components of the normal mammary gland. Endocrinology 108 825-830.

He WW, Kumar MV \& Tindall DJ 1991 A frameshift mutation in the androgen receptor gene causes complete androgen insensitivity in the testicular-feminized mouse. Nucleic Acids Research 19 2373-2378.

Heuberger B, Fitzka I, Wasner G \& Kratochwil K 1982 Induction of androgen receptor formation by epitheliummesenchyme interaction in embryonic mouse mammary gland. PNAS 79 2957-2961.

Horseman ND, Zhao W, Montecino-Rodriguez E, Tanaka M, Nakashima K, Engle SJ, Smith F, Markoff E \& Dorshkind K 1997 Defective mammopoiesis, but normal hematopoiesis, in mice with a targeted disruption of the prolactin gene. EMBO Journal 16 6926-6935.

Hoshino K 1978 Mammary transplantation and its histogenesis in mice. In Physiology of Mammary Glands, pp 163-228. Eds A Yokoyama, H Mizuno \& H Nagasawa. Baltimore, MD: University Park Press.

Howard BA \& Gusterson BA 2000 Human breast development. Journal of Mammary Gland Biology and Neoplasia 5 119-137.

Humphreys RC, Lydon J, O’Malley BW \& Rosen JM 1997 Mammary gland development is mediated by both stromal and epithelial progesterone receptors. Molecular Endocrinology 11 801-811.

Ichinose RR \& Nandi S 1966 Influence of hormones on lobuloalveolar differentiation of mouse mammary glands in vitro. Journal of Endocrinology 35 331-340.

Imagawa W, Bandyopadhyay GK \& Nandi S 1990 Regulation of mammary epithelial cell growth in mice and rats. Endocrine Reviews 11 494-523.

Jensen HM \& Wellings SR 1976 Preneoplastic lesions of the human mammary gland transplanted into the nude athymic mouse. Cancer Research 36 2605-2610.

Kratochwil K 1969 Organ specificity in mesenchymal induction demonstrated in the embryonic development of the mammary gland of the mouse. Developmental Biology 20 46-71.

Kratochwil K 1971 In vitro analysis of the hormonal basis for the sexual dimorphism in the embryonic development of the mouse mammary gland. Journal of Embryology and Experimental Morphology 25 141-153.
Kratochwil K 1977 Development and loss of androgen responsiveness in the embryonic rudiment of the mouse mammary gland. Developmental Biology 61 358-365.

Kratochwil K 1987 Tissue combination and organ culture studies in the development of the embryonic mammary gland. In Developmental Biology: A Comprehensive Synthesis, pp 315-334. Ed RBL Gwatkin. New York: Plenum Press.

Kratochwil K \& Schwartz P 1976 Tissue interaction in androgen response of embryonic mammary rudiment of mouse: identification of target tissue of testosterone. PNAS 73 4041-4044.

Krege JH, Hodgin JB, Couse JF, Enmark E, Warner M, Mahler JF, Sar M, Korach KS, Gustafsson JA \& Smithies O 1998 Generation and reproductive phenotypes of mice lacking estrogen receptor beta. PNAS 95 15677-15682.

Kulkarni AB, Huh CG, Becker D, Geiser A, Lyght M, Flanders KC, Roberts AB, Sporn MB, Ward JM \& Karlsson S 1993 Transforming growth factor beta 1 null mutation in mice causes excessive inflammatory response and early death. PNAS 90 770-774.

Luetteke NC, Qiu TH, Fenton SE, Troyer KL, Riedel RF, Chang A \& Lee DC 1999 Targeted inactivation of the EGF and amphiregulin genes reveals distinct roles for EGF receptor ligands in mouse mammary gland development. Development 126 2739-2750.

Lydon JP, DeMayo FJ, Funk CR, Mani SK, Hughes AR, Montgomery CA, Shyamala G, Conneely OM \& O’Malley BW 1995 Mice lacking progesterone receptor exhibit pleiotropic reproductive abnormalities. Genes and Development 9 2266-2278.

McGrath CM 1983 Augmentation of response of normal mammary epithelial cells to estradiol by mammary stroma. Cancer Research 43 1355-1360.

McManaman JL \& Neville MC 2003 Mammary physiology and milk secretion. Advanced Drug Delivery Reviews 55 629-641.

McManus MJ \& Welsch CW 1981 Hormone-induced ductal DNA synthesis of human breast tissues maintained in the athymic nude mouse. Cancer Research 41 3300-3305.

McManus MJ \& Welsch CW 1984 The effect of estrogen, progesterone, thyroxine, and human placental lactogen on DNA synthesis of human breast ductal epithelium maintained in athymic nude mice. Cancer 54 1920-1927.

Mailleux AA, Spencer-Dene B, Dillon C, Ndiaye D, SavonaBaron C, Itoh N, Kato S, Dickson C, Thiery JP \& Bellusci S 2002 Role of FGF10/FGFR2b signaling during mammary gland development in the mouse embryo. Development 129 53-60.

Miettinen PJ, Berger JE, Meneses J, Phung Y, Pedersen RA, Werb Z \& Derynck R 1995 Epithelial immaturity and multiorgan failure in mice lacking epidermal growth factor receptor. Nature $376337-341$.

Moll R, Franke WW, Schiller DL, Geiger B \& Krepler R 1982 The catalog of human cytokeratin polypeptides: patterns of expression of specific cytokeratins in normal epithelia, tumors, and cultured cells. Cell 31 11-24.

Mueller SO, Clark JA, Myers PH \& Korach KS 2002 Mammary gland development in adult mice requires epithelial and stromal estrogen receptor alpha. Endocrinology 143 $2357-2365$. 
Nandi S 1958 Endocrine control of mammary gland development and function in the $\mathrm{C} 3 \mathrm{H} / \mathrm{He} \mathrm{Crgl}$ mouse. Journal of the National Cancer Institute 21 1039-1063.

Neville MC, McFadden TB \& Forsyth I 2002 Hormonal regulation of mammary differentiation and milk secretion. Journal of Mammary Gland Biology and Neoplasia 7 49-66.

Niranjan B, Buluwela L, Yant J, Perusinghe N, Atherton A, Phippard D, Dale T, Gusterson B \& Kamalati T 1995 HGF/ $\mathrm{SF}$ : a potent cytokine for mammary growth, morphogenesis and development. Development 121 2897-2908.

Olumi AF, Grossfeld GD, Hayward SW, Carroll PR, Tlsty TD \& Cunha GR 1999 Carcinoma-associated fibroblasts direct tumor progression of initiated human prostatic epithelium. Cancer Research 59 5002-5011.

Ormandy CJ, Camus A, Barra J, Damotte D, Lucas B, Buteau H, Edery M, Brousse N, Babinet C, Binart N \& Kelly PA 1997 Null mutation of the prolactin receptor gene produces multiple reproductive defects in the mouse. Genes and Development 11 167-178.

Outzen HC \& Custer RP 1975 Growth of human normal and neoplastic mammary tissues in the cleared mammary fat pad of the nude mouse. Journal of the National Cancer Institute $\mathbf{5 5}$ 1461-1466.

Parmar H, Young P, Emerman JT, Neve RM, Dairkee S \& Cunha GR 2002 A novel method for growing human breast epithelium in vivo using mouse and human mammary fibroblasts. Endocrinology 143 4886-4896.

Popnikolov NK, Yang J, Guzman RC, Swanson SM, Thordarson G, Collins G, Talamantes F \& Nandi S 1995 In vivo growth stimulation of collagen gel embedded normal human and mouse primary mammary epithelial cells. Journal of Cellular Physiology 163 51-60.

Popnikolov N, Yang J, Liu A, Guzman R \& Nandi S 2001 Reconstituted normal human breast in nude mice: effect of host pregnancy environment and human chorionic gonadotropin on proliferation. Journal of Endocrinology 168 487-496.

Propper A 1968 Relations épidermo-mésodermiques dans la différenciation de l'ébauche mammaire d'embryon de lapin. Annals of Embryology and Morphology 1 151-160.

Propper AY 1978 Wandering epithelial cells in rabbit embryo milk line. Developmental Biology 67 225-231.

Propper A \& Gomot L 1967 Interactions tissulaires au cours de l'organogenèse de la glande mammaire de l'embryon de lapin. Comptes Rendus de l'Académie des Sciences (Paris) 264 2573-2575.

Propper A \& Gomot L 1973 Control of chick epidermis differentiation by rabbit mammary mesenchyme. Experientia 29 1543-1544.

Radice GL, Ferreira-Cornwell MC, Robinson SD, Rayburn H, Chodosh LA, Takeichi M \& Hynes RO 1997 Precocious mammary gland development in P-cadherin-deficient mice. Journal of Cell Biology 139 1025-1032.

Reece-Smith H, Homan WP, Du Toit DF, McShane P \& Morris PJ 1981 A technique for transplanting pancreatic islets as a vascularized graft and prevention of rejection with cyclosporin A. Transplantation 31 442-444.
Richert MM, Schwertfeger KL, Ryder JW \& Anderson SM 2000 An atlas of mouse mammary gland development. Journal of Mammary Gland Biology and Neoplasia 5 227-241.

Roberts AB \& Sporn MB 1990 The transforming growth factor-betas. In Peptide Growth Factors and their Receptors, pp 419-472. Eds MB Sporn \& AB Roberts. Heidelberg: Springer-Verlag.

Robinson GW \& Hennighausen L 1997 Inhibins and activins regulate mammary epithelial cell differentiation through mesenchymal-epithelial interactions. Development 124 27012708.

Robinson SD, Silberstein GB, Roberts AB, Flanders KC \& Daniel CW 1991 Regulated expression and growth inhibitory effects of transforming growth factor- $\beta$ isoforms in mouse mammary gland development. Development 113 867-878.

Ronnov-Jessen L, Petersen OW \& Bissell MJ 1996 Cellular changes involved in conversion of normal to malignant breast: importance of the stromal reaction. Physiological Reviews 76 69-125.

Russo J \& Russo IH 1987 Development of human mammary gland. In The Mammary Gland Development, Regulation and Function, pp 67-96. Eds MC Neville \& CW Daniel. New York: Plenum Press.

Russo J, Gusterson BA, Rogers AE, Russo IH, Wellings SR \& van Zwieten MJ 1990 Comparative study of human and rat mammary tumorigenesis. Laboratory Investigation $6 \mathbf{2}$ 244-278.

Sakakura T 1987 Mammary embryogensis. In The Mammary Gland: Development, Regulation and Function, pp 37-66. Eds CW Neville \& MC Daniel. New York: Plenum Press.

Sakakura T, Nishizuka Y \& Dawe CJ 1976 Mesenchymedependent morphogenesis and epithelium-specific cytodifferentiation in mouse mammary gland. Science 194 1439-1441.

Sakakura T, Sakagami Y \& Nishizuka Y 1982 Dual origin of mesenchymal tissues participating in mouse mammary gland embryogenesis. Developmental Biology 91 202-207.

Schmeichel KL \& Bissell MJ 2003 Modeling tissue-specific signaling and organ function in three dimensions. Journal of Cell Science 116 2377-2388.

Sheffield LG \& Welsch CW 1986 Transplantation of bovine mammary tissue to athymic nude mice: growth subcutaneously and in mammary gland-free fat pads. Journal of Dairy Science 69 1141-1147.

Sheffield LG \& Welsch CW 1988 Transplantation of human breast epithelia to mammary-gland-free fat-pads of athymic nude mice: influence of mammotrophic hormones on growth of breast epithelia. International Journal of Cancer $\mathbf{4 1}$ 713-719.

Shyamala G 1997 Roles of estrogen and progesterone in normal mammary gland development. Insights from progesterone receptor null mutant mice and in situ localization. Trends in Endocrinology and Metabolism 8 34-39.

Shyamala G, Barcellos-Hoff MH, Toft D \& Yang X 1997 In situ localization of progesterone receptors in normal mouse mammary glands: absence of receptors in the connective and adipose stroma and a heterogeneous distribution in the epithelium. Journal of Steroid Biochemistry and Molecular Biology 63 251-259. 
Silberstein GB, Van Horn K, Shyamala G \& Daniel CW 1994 Essential role of endogenous estrogen in directly stimulating mammary growth demonstrated by implants containing pure antiestrogens. Endocrinology 134 84-90.

Soriano JV, Pepper MS, Orci L \& Montesano R 1998 Roles of hepatocyte growth factor/scatter factor and transforming growth factor-betal in mammary gland ductal morphogenesis. Journal of Mammary Gland Biology and Neoplasia 3 133-150.

Stach-Chilf E, Warchol JB \& Pilgrim C 1981 The fine structure of the neural lobe of the mouse after transplantation under the kidney capsule. Cell and Tissue Research 219 417-423.

Taguchi O, Cunha GR, Lawrence WD \& Robboy SJ 1984 Timing and irreversibility of Mullerian duct inhibition in the embryonic reproductive tract of the human male. Developmental Biology 106 394-398.

Taylor PJ, Shearer M \& Stoker MG 1977 Growth requirements of human mammary epithelial cells in culture. International Journal of Cancer 20 903-908.

Thiede MA \& Rodan GA 1988 Expression of a calciummobilizing parathyroid hormone-like peptide in lactating mammary tissue. Science 242 278-280.

Thomas TZ, Chapman SM, Hong W, Gurusingfhe C, Mellor SL, Fletcher R, Pedersen J \& Risbridger GP 1998 Inhibins, activins, and follistatins: expression of mRNAs and cellular localization in tissues from men with benign prostatic hyperplasia. Prostate 34 34-43.

Topper YJ \& Freeman CS 1980 Multiple hormone interactions in the developmental biology of the mammary gland. Physiological Reviews 60 1049-1106.

Ulich TR, Yi ES, Cardiff R, Yin S, Bikhazi N, Biltz R, Morris CF \& Pierce GF 1994 Keratinocyte growth factor is a growth factor for mammary epithelium in vivo. The mammary epithelium of lactating rats is resistant to the proliferative action of keratinocyte growth factor. American Journal of Pathology 144 862-868.

Veltmaat JM, Mailleux AA, Thiery JP \& Bellusci S 2003 Mouse embryonic mammogenesis as a model for the molecular regulation of pattern formation. Differentiation 71 1-17.

Weizsacker M, Nagamune A, Rathmer K \& Wechsler W 1983 Brain tumor growth and response to chemotherapy in the subrenal capsule assay. Journal of Cancer Research and Clinical Oncology 106 229-233.
Welsch CW, O'Connor DH, Aylsworth CF \& Sheffield LG 1987 Normal but not carcinomatous primary rat mammary epithelium: readily transplanted to and maintained in the athymic nude mouse. Journal of the National Cancer Institute 78 557-565.

Wiesen JF, Young P, Werb Z \& Cunha GR 1999 Signaling through the stromal epidermal growth factor receptor is necessary for mammary ductal development. Development 126 335-344.

Wysolmerski JJ, McCaughern-Carucci JF, Daifotis AG, Broadus AE \& Philbrick WM 1995 Overexpression of parathyroid hormone-related protein or parathyroid hormone in transgenic mice impairs branching morphogenesis during mammary gland development. Development 121 3539-3547.

Wysolmerski J, Philbrick W, Dunbar M, Lanske B, Kronenberg H \& Broadus A 1998 Rescue of the parathyroid hormonerelated protein knockout mouse demonstrates that parathyroid hormone-related protein is essential for mammary gland development. Development 125 1285-1294.

Yang J, Guzman R, Richards J, Jentoft V, DeVault MR, Wellings SR \& Nandi S 1980 Primary culture of human mammary epithelial cells embedded in collagen gels. Journal of the National Cancer Institute 65 337-343.

Yang J, Guzman RC, Popnikolov N, Bandyopadhyay GK, Christov K, Collins G \& Nandi S 1994 Phenotypic characterization of collagen gel embedded primary human breast epithelial cells in athymic nude mice. Cancer Letters $\mathbf{8 1}$ 117-127.

Yang J, Liu A, Dougherty C, Chen X, Guzman R \& Nandi S 2000 Estrogen and progesterone receptors can be maintained in normal human breast epithelial cells in primary culture and after transplantation into nude mice. Oncology Reports 7 $17-21$.

Yang Y, Spitzer E, Meyer D, Sachs M, Niemann C, Hartmann G, Weidner KM, Birchmeier C \& Birchmeier W 1995 Sequential requirement of hepatocyte growth factor and neuregulin in the morphogenesis and differentiation of the mammary gland. Journal of Cell Biology 131 215-226.

Zhang HZ, Bennett JM, Smith KT, Sunil N \& Haslam SZ 2002 Estrogen mediates mammary epithelial cell proliferation in serum-free culture indirectly via mammary stroma-derived hepatocyte growth factor. Endocrinology 143 3427-3434. 